\title{
(2) OPEN ACCESS \\ DNA damage repair as a target in pancreatic cancer: state-of-the-art and future perspectives
}

\author{
Lukas Perkhofer (10), 'Johann Gout (10),' Elodie Roger (1) ,' \\ Fernando Kude de Almeida, ${ }^{2}$ Carolina Baptista Simões, ${ }^{3}$ Lisa Wiesmüller, ${ }^{4}$ \\ Thomas Seufferlein, ${ }^{1}$ Alexander Kleger (1) ${ }^{1}$
}

'Department of Internal Medicine 1, University Hospital Ulm, Ulm, Germany ${ }^{2}$ Universidade Federal de Ciências da Saúde de Porto Alegre, Porto Alegre, RS, Brazil ${ }^{3}$ Hospital de Santa Maria, Centro Hospitalar De Lisboa Norte E.P.E. (CHLN), Gastroenterology, Lisboa, Portugal

${ }^{4}$ Department of Obstetrics and Gynecology, Ulm University,

Ulm, Germany

\section{Correspondence to}

Professor Thomas Seufferlein, Department of Internal Medicine 1, University Hospital Ulm, Ulm 89081, Germany;

thomas.seufferlein@uniklinikulm.de

TS and AK contributed equally.

Received 17 February 2020

Revised 12 June 2020

Accepted 11 July 2020

Published Online First

27 August 2020

\begin{abstract}
Complex rearrangement patterns and mitotic errors are hallmarks of most pancreatic ductal adenocarcinomas (PDAC), a disease with dismal prognosis despite some therapeutic advances in recent years. DNA double-strand breaks (DSB) bear the greatest risk of provoking genomic instability, and DNA damage repair (DDR) pathways are crucial in preserving genomic integrity following a plethora of damage types. Two major repair pathways dominate DSB repair for safeguarding the genome integrity: non-homologous end joining and homologous recombination (HR). Defective $H R$, but also alterations in other DDR pathways, such as BRCA1,BRCA2, ATM and $P A L B 2$, occur frequently in both inherited and sporadic PDAC. Personalised treatment of pancreatic cancer is still in its infancy and predictive biomarkers are lacking. DDR deficiency might render a PDAC vulnerable to a potential new therapeutic intervention that increases the DNA damage load beyond a tolerable threshold, as for example, induced by poly (ADP-ribose) polymerase inhibitors. The Pancreas Cancer Olaparib Ongoing (POLO) trial, in which olaparib as a maintenance treatment improved progression-free survival compared with placebo after platinum-based induction chemotherapy in patients with PDAC and germline BRCA1/2 mutations, raised great hopes of a substantially improved outcome for this patient subgroup. This review summarises the relationship between DDR and PDAC, the prevalence and characteristics of DNA repair mutations and options for the clinical management of patients with PDAC and DNA repair deficiency.
\end{abstract}

\section{INTRODUCTION}

Pancreatic ductal adenocarcinoma (PDAC) is an exceptional malignancy with a distinct biology and epidemiology. It is nowadays the fourth leading cause of cancer-related deaths in the Western world and one of the few cancers with a rising incidence. PDAC has shown the least therapeutic progress out of all major GI cancers over the last decades. ${ }^{1}$ Various routes involving distinct precursor lesions guide PDAC development: (i) acinar cells undergo ductal reprogramming, forming metaplastic ducts which give rise to pancreatic intraepithelial neoplasia (PanIN1-3) with an increasing degree of dysplasia; (ii) pancreatic duct cells acquire oncogenic events that accelerate an aggressive PDAC formation $^{2}$; (iii) mutations in pancreatic ducts, depending on the mutational make-up, lead to cystic precursor tumours: the mucinous cystic neoplasms and the intraductal papillary mucinous neoplasms (IPMN), each following separate genetic routes towards PDAC. The dismal prognosis of PDAC is mainly caused by a unique molecular complexity including (i) a desmoplastic, immunosuppressive and stroma-enriched environment; (ii) a high level of intratumoural and intertumoural heterogeneity $^{3}$; (iii) a condition ultimately leading to early metastasis and high chemoresistance. Numerous, but not all clinical trials on PDAC have failed over the last decade. ${ }^{4}$ Single gemcitabine, gemcitabine/ capecitabine and modified folinic acid, fluouracil, irinotecan, oxaliplatin (FOLFIRINOX) are now consolidated adjuvant treatment options. ${ }^{56}$ Neoadjuvant and perioperative treatment concepts are currently being investigated. ${ }^{7}$ In advanced PDAC, FOLFIRINOX and the combination of nanosized albumin-bound paclitaxel (nab-PTX)/gemcitabine are superior to gemcitabine alone in first-line therapy and are thus considered the standard of care. ${ }^{89}$ However, median overall survival (mOS) in advanced disease rarely exceeds 1 year, resulting in a 5 -year OS of $<10 \%$ for all stages. ${ }^{3}$ This underpins the necessity for more innovative, effective and targeted regimens. However, in contrast to various other cancers, tailored approaches have been largely disappointing in PDAC. ${ }^{10-13}$ Activating KRAS mutations are major drivers of malignant growth in PDAC, and although yet undruggable, first promising developments have been made. ${ }^{14}$ The oncogenic KRAS dosage also regulates diverse phenotypes in PDAC, leading to different routes of tumourigenesis permitted by the loss of distinct tumour suppressor gene pathways (eg, TP53, CDKN2A, SMAD4). ${ }^{15}$ Accordingly, oncogenic KRAS may synergise with additional tumour suppressor mutations to deregulate double-strand break (DSB) repair and subsequently induce genomic instability. ${ }^{16}$

${ }^{17}$ Besides, a tremendously high number of passenger mutations establishes the high intratumoural and intertumoural heterogeneity. To approach this heterogeneity, transcriptional profiling of purified pancreatic cancer epithelial cells allowed a certain degree of subgrouping, having led to various partly overlapping classifications according to Collisson et $a l,{ }^{18}$ Moffitt $e t a l^{19}$ and Bailey et al. ${ }^{20}$ The basal-like and classical subtypes have meanwhile evolved as the most robust transcriptional classifier. However, transcriptional phenotypes could be recently integrated with genomic alterations by using wholegenome analysis from purified epithelium of primary and metastatic human PDAC together with
To cite: Perkhofer L, Gout J, Roger $\mathrm{E}$, et al. Gut 2021;70:606-617. 
single-cell RNA sequencing. Thereby, the Notta group revealed that molecular subtypes are specifically linked to copy number aberrations, for example, in the KRAS gene, which in turn additionally drive genomic instability. ${ }^{21}$ These observations indicate that genomic aberrations can define the molecular subtype, and PDAC heterogeneity as well as evolution during disease progression is caused by certain mutational triggers. ${ }^{21}$ To genomically classify PDAC according to patterns of variation in chromosomal structure, four subtypes have been defined and also allowed predictions in terms of a given treatment. Those subtypes have been termed (i) 'stable', (ii) 'locally rearranged', (iii) 'scattered' and (iv) 'unstable. ${ }^{16}$ The latter accounts for around 14\% of human PDACs and harbours mutations in the genes responsible for DNA repair that are involved in the so-called DNA damage repair (DDR), such as BRCA1/2, PALB2 and ATM. Mutations in these genes also cluster in inherited forms of PDAC.22 Thus, a significant proportion of human PDACs with either somatic or germline mutations in DDR genes might benefit from tailored, targeted therapies. These aspects form the focus of the current review.

\section{DNA DAMAGE REPAIR AND CANCER}

Preserving the integrity of our DNA is eminent in preventing genomic instability, a hallmark of cancer, various chronic diseases and the normal process of ageing. ${ }^{23}$ DNA damage is a common event and must undergo immediate repair in order to ensure the exact transfer of genetic information during cell division. The inability of the DDR to repair following endogenous and exogenous insults can lead to (i) an accumulation of genomic defects, (ii) subsequent malignant transformation, (iii) cancer progression and (iv) further impairment of the DNA repair capacity. By contrast, during tumour progression or on therapyinduced tumour evolution, the DDR machinery can be reconstituted to assign new growth advantages to outgrowing tumour clones with disturbed genomic integrity. Repair mechanisms include the detection and excision of the defect, the rejoining of DNA ends and the reconstruction of the sequence based on a DNA matrix (figure 1). Basically, DNA lesions can occur in two major ways, affecting either a single-strand break (SSB) or DSB or mono-adducts and interstrand crosslinks, respectively. Damage affecting a single DNA strand can be removed either by base excision, mismatch (MMR $)^{24}$ or nucleotide excision repair (NER), ${ }^{25}$ all of which use the sister strand as a template (figure 1). Conversely, DSBs or crosslinked DNA strands (eg, caused by platinum agents or irradiation) require partial strand substitution, a process that is much more complex and susceptible to errors. ${ }^{26}$ It is noteworthy that the accumulation of unresolved SSBs inexorably induces DSB formation, namely when encountering a replication fork. Two main mechanisms affect DSB repair, namely non-homologous end joining (NHEJ) and homologous recombination (HR) (figure 1). While NHEJ is a more error-prone form of DSB repair, in which a DNA segment is removed and both ends are adjoined without consideration of homology, $\mathrm{HR}$ is an accurate process that uses the sister chromatid as a repair template. ${ }^{27}$ Herein, the MRN (Mre11, Rad50 and Nbs1 proteins) complex makes up the core of the initial DSB repair machinery as an upstream effector of HR and partially NHEJ. This complex crucially participates in all DSB repair events such as (i) DNA damage sensing, (ii) DDR protein recruitment to the damaged site, (iii) cell cycle checkpoints activation and (iv) damage repair. ${ }^{28}{ }^{29}$ Accordingly, DSBs detected by the MRN complex activate the cell cycle regulatory serine/

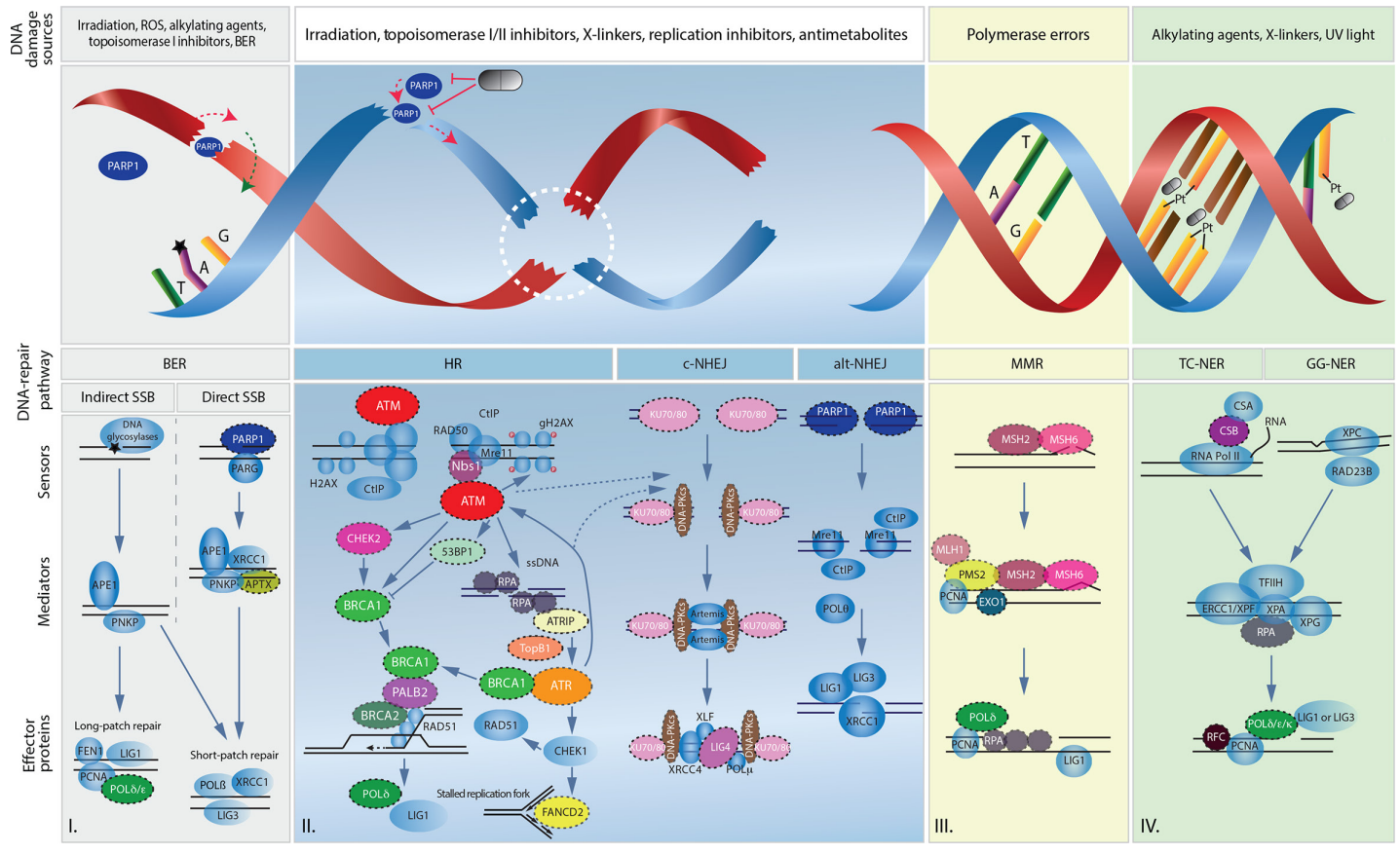

Figure 1 Overview of main DNA lesions and their related DNA damage repair pathways. Schematic representation of I. single-strand break repair by direct and indirect base excision repair, II. double-strand break repair by homologous recombination and non-homologous end joining, III. replication error repair by mismatch repair and IV. DNA adducts repair by either transcription-coupled nucleotide excision repair (TC-NER) or global genomic nucleotide excision repair (GG-NER). Symbolic pills show potential targeted therapeutic interventions by PARP inhibition and platinum agents (Pt). Black stars represent an indirect single-strand break. Dashed circles emphasize proteins found to be mutated in human pancreatic ductal adenocarcinoma. Dashed lines represent the regulatory role of ATM and ATR on non-homologous end joining. alt-NHEJ, alternative non-homologous end joining; BER, base excision repair; c-NHEJ, canonical non-homologous end joining; MMR, mismatch repair; ROS, reactive oxygen Species; SSB, single-strand break. 
threonine kinases ataxia telangiectasia mutated (ATM) and ATM and Rad3-related protein (ATR) to allow the formation of protruding 3' ends at both sides of the break. ${ }^{24}$ Subsequently, ATM activates CHK2, which arrests cell cycle progression, interacts with TP53 that is responsible for cell cycle and apoptosis control and contributes to regulating BRCA1 in DNA repair. ${ }^{30}$ The MRN complex also attracts BRCA1 to the DNA damage site, supporting DNA resection, forming the adjoining 3' ends and recruiting PALB2 and BRCA2. ${ }^{31}$ This newly formed complex of BRCA1, PALB2 and BRCA2 finally activates RAD51, that is responsible for binding single-stranded DNA segments and invading the homologous sequences in the sister chromatid. ${ }^{31}$ Alternatively, ATR is activated by the presence of a DNA crosslinking adduct phosphorylating the Fanconi anaemia (FA) core complex, which helps to excise the defect. ${ }^{32}$ During this DNA crosslink repair process involving NER, DSBs are generated in the proximity of the incised oligonucleotide. ${ }^{32}$ Subsequently, this accumulation of DSBs requires repair, particularly by HR and not NHEJ. ${ }^{33} 34$ Consequently, mutations in HR genes (such as $B R C A 1, B R C A 2$, XRCC2 and XRCC3) can further exhibit hypersensitivity to crosslinking agents (figure 1). ${ }^{32}$

In summary, a plethora of distinct and tailored repair mechanisms work to preserve genomic integrity in healthy and in cancerous cells. Any failure of the DDR leads to a subsequent accumulation of mutations as well as structural aberrations, usually generating particularly aggressive tumours. It is of great importance that the sole dependence on the remaining DDR pathways has yielded several conceptual approaches such as synthetic lethality for discovering and characterising cancerspecific vulnerabilities in customised interventions. ${ }^{35}$

\section{DNA DAMAGE REPAIR DEFECTS AND PANCREATIC CANCER}

The incidence of PDAC shows significant variations from a geographic perspective, with the highest in high-income countries. ${ }^{36}$ Although the cause of PDAC is complex and multifactorial, a variety of inherited and non-inherited risk factors have been described, some of which may explain these variations. Non-inherited risk factors include chronic pancreatitis, diabetes mellitus, smoking, alcohol consumption, obesity and possibly Helicobacter pylori infection. ${ }^{3}$ Apart from these, various genes have been associated with increased PDAC susceptibility. ${ }^{22}$

Sporadic pancreatic cancer with somatic DDR gene mutations Tumour biology in PDAC is determined by the type of mutations and structural aberrations and not by their pathogenic or

somatic occurrence, ${ }^{37}$ the latter dominating the most frequently occurring sporadic PDAC. In fact, biallelic inactivation, zygositydependent phenotype penetrance and sensitivity to poly (ADPribose) polymerase (PARP) inhibition, as shown for BRCA1/2 in PDAC, are frequently associated with genomic features such as dramatic chromosomal rearrangements, indicating a deficient HR profile. ${ }^{1637}$ Particularly in pancreatic carcinogenesis, single mitotic errors as well as distinct genomic rearrangements such as chromothripsis (an unstable subtype enriched feature) can lead to a dramatic loss of genetic information accompanied by a simultaneous loss of function of several tumour suppressors. In turn, rapid and synchronous clonogenic escape is thought to establish the metastatic disease. ${ }^{38}$ Large-scale genomic analysis revealed 63 genetic alterations per single PDAC, with 'DNA damage control' being one of the most prominent terms (figure 2). ${ }^{39}$ Another study reported either an unstable genome or a BRCAness mutational signature in $24 \%$ of analysed PDACs, with $17 \%$ germline and $29 \%$ somatic mutations in $B R C A 1 / 2$, ATM or PALB2. ${ }^{16}$ Basically, BRCAness encompasses defects in the HR pathway, mimicking the consequences of BRCA1 or $B R C A 2$ loss. ${ }^{40}$ Overall, ATM appears to be the most frequently mutated DDR gene in somatically mutated sporadic PDAC, with an overall mutational frequency of approximately 4\%, followed by BRCA2, STK11 and BRCA1 (figure 2). Loss of ATM occurs in precancerous lesions such as PanINs or IPMNs and in primary tumours, underpinning its crucial role in genomic integrity. ${ }^{4142}$ The ultimate therapeutic strategy for PDAC is the delineation of patient subgroups who might be susceptible to an interference with the DDR due to the intrinsically high DNA damage load, leading to a further increase beyond a tolerable threshold.

\section{DDR gene mutations in the germline of patients with pancreatic cancer \\ Familial pancreatic cancer and hereditary pancreatic cancer syndromes}

Unlike sporadic PDACs, up to $10 \%$ of the cases cluster in families, with at least two first-degree relatives (FDR) being affected. These cases are designated as familial pancreatic cancers (FPC). The risk of developing PDAC in relatives fulfilling the FPC criteria increases with the number of affected FDRs by 4.6, 6.4 and up to 32-fold for 1, 2 and $\geq 3$ FDRs, respectively, compared with the whole population. ${ }^{43}$ Nevertheless, $80 \%-90 \%$ of the genetic events leading to FPC remain unknown, leaving as few as $10 \%-20 \%$ with a clearly identifiable germline mutation. This makes it difficult to properly distinguish FPCs from apparently

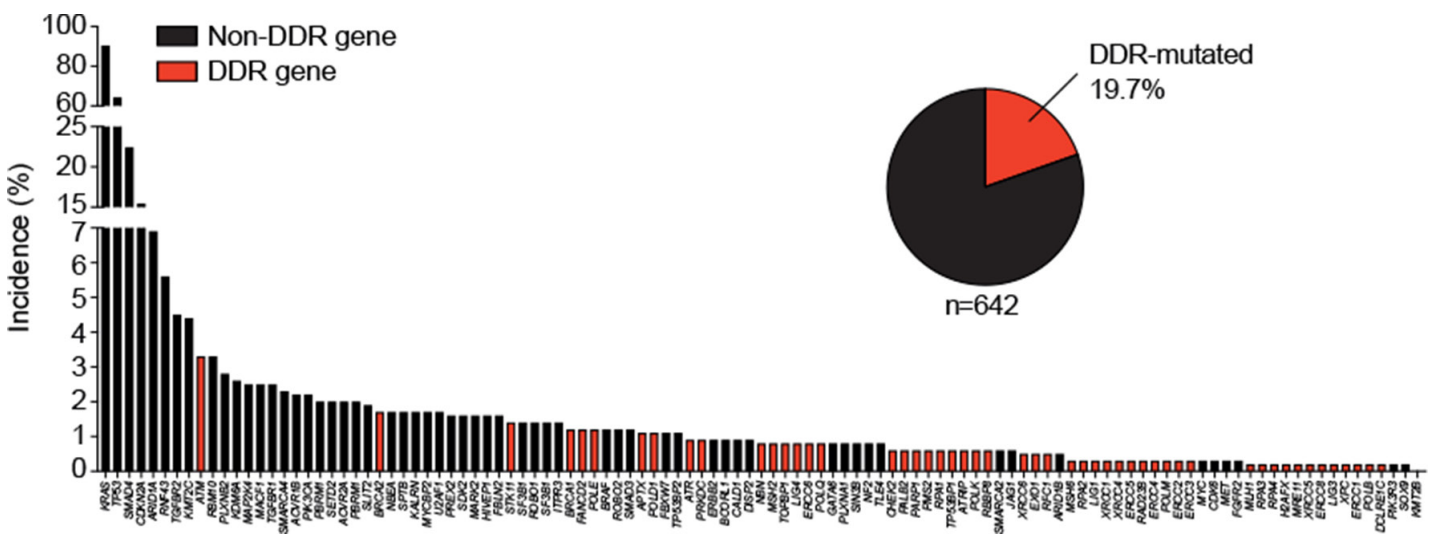

Figure 2 Frequency of gene alterations in primary pancreatic ductal adenocarcinomas. Three available pancreatic cancer sequencing data sets ${ }^{123}$ $124125(n=751)$ were assessed for somatic gene mutations (panel of 118 genes from ${ }^{16} 123$ and additionally extended in more detail for DNA damage repair genes from cBioPortal). DDR, DNA damage repair. 
Table 1 Frequency of the most common deleteriously mutated genes in familial pancreatic cancer

\begin{tabular}{lllll}
\hline Gene & $\begin{array}{l}\text { Zhen } \text { et } a^{44} \\
(\mathbf{n}=515)\end{array}$ & $\begin{array}{l}\text { Roberts et } \\
a^{22}(\mathbf{n}=166)\end{array}$ & $\begin{array}{l}\text { Takai et } a l^{45} \\
(\mathbf{n}=54)\end{array}$ & $\begin{array}{l}\text { Mutation } \\
\text { prevalence } \\
(\%)\end{array}$ \\
\hline BRCA2 & 19 & n.a. & 3 & 3.9 \\
\hline ATM & n.a. & 4 & 2 & 2.7 \\
CDKN2A & 13 & n.a. & n.a. & 2.5 \\
\hline BRCA1 & 6 & n.a. & n.a. & 1.2 \\
PALB2 & 3 & n.a. & 2 & 0.9 \\
\hline
\end{tabular}

Mutations data were analysed from three familial pancreatic cancer cohorts (735 samples).

n.a., not applicable.

sporadic PDACs. Specifically, inheritance can be frequently attributed to germline DDR gene mutations (ATM, BRCA1, BRCA2, MLH1, MSH2, PALB2, PMS2 and STK11) and to mutations in classical cancer susceptibility genes such as CDKN2A or TP53. Table 1 summarises the frequencies of the most relevant FPC-causing genes. 22445

Moreover, several inherited cancer predisposition syndromes are characterised by usually monoallelic, dominantly inherited autosomal mutations that predispose to PDAC and other cancers such as prostate, breast and ovarian cancer (eg, BRCA1/2 mutations). ${ }^{46} 47$ The majority of the underlying germline mutations are well-characterised, such as Peutz-Jeghers caused by STK11 mutations or Lynch syndrome caused by MLH1 and MSH2 mutations. Furthermore, the risk of PDAC is increased in familial adenomatous polyposis (usually associated with APC mutations), familial atypical multiple-mole melanoma syndrome (FAMMM; CDK2NA mutations), hereditary pancreatitis (PRSS1 and SPINK1 mutations) and Li-Fraumeni syndrome (TP53 mutations). ${ }^{48-50}$ It is to be noted that Peutz-Jeghers syndrome-related PDACs are mostly, but not exclusively, associated with the IPMN precursor lesion pathway. ${ }^{51}$ Finally, chronic pancreatitis in patients with cystic fibrosis related to the CFTR gene has been associated with a moderately increased incidence of PDAC in mutation carriers. ${ }^{52}$

Sporadic pancreatic cancer with germline mutations

Interestingly, in about 3.9\%-13.5\% of patients with apparently sporadic PDAC, DDR gene mutations can be detected in the germline, although negative family history of cancer. ${ }^{53} 54555556$

57 This mirrors an incomplete penetration, rather than a de novo mutation in the germline. With a frequency up to $3.4 \%,{ }^{56}$ ATM serine/threonine kinase is the most frequently mutated DDR gene in this group (table 2). Biallelic mutations in ATM cause a syndrome known as ataxia telangiectasia that predisposes to various cancers, including PDAC (twofold to threefold increased risk). ${ }^{58} 59$ BRCA1/2 mutations are also frequent in this subgroup and have the highest prevalence (12.1\%) in Ashkenazi Jews. ${ }^{60}$ A recent study also identified germline mutations in $7.3 \%$ of patients with IPMN and associated them with an increased risk of developing PDAC, ${ }^{42}$ for instance, PALB2, which codes for a BRCA2-interacting protein essential for the DSB repair function. Monoallelic germline mutations in PALB2 are also associated with breast cancer. ${ }^{61}$ Biallelic germline mutations result in a rare subtype of FA (FA-N) associated with a severe predisposition to paediatric malignancies. ${ }^{62}$

\section{BRCANESS REVISITED}

Most of the DDR genes mutated in PDAC are crucial for the proper functioning of the HR pathway. Alterations in these genes lead to a homologous recombination-deficient (HRD) phenotype within a given tumour defining the term BRCAness. This defect can arise following certain genomic, epigenetic or post-translational alterations in certain DDR genes. Recently, it has been shown that loss-of-function alterations in BRCA1/2 are an indispensable initiating event in so-called BRCA-associated cancer types (pancreatic, prostate, breast or ovarian cancer). Thus, the tumour lineage, together with a given mutation, determines the tumour biology, and, subsequently, therapeutic decision-making in non-BRCA-associated cancers, for example, $B R C A 1 / 2$ mutations, is carried out in a biologically neutral manner. ${ }^{37}$ Molecularly, the BRCA1/PALB2/BRCA2 complex activates RAD51 to allow the incursion of the sister chromatid homologous sequences, a crucial step during HR (as described before). Similarly, ATM or ATR loss-driven DSB sensor defects lead to failure of this repair complex (figure 1). Therefore, any disruption of HR influences cells to rely on error-prone DNA repair pathways (such as NHEJ) for DSB repair, cumulating in augmented genomic instability. The term HRDness extends this phenotypic spectrum to other somatic or germline mutations causing HR defects, including non-BRCA-related phenotypes. ${ }^{63}$ Along this line, a highly promising concept could be the chemical induction of HRDness using certain therapeutics (eg, ATM or ATR inhibitors) and subsequently targeting the respective tumour with classical DNA-damaging agents. However, testing

Table 2 Frequency of germline mutations in DNA damage repair and cell cycle control genes in sporadic pancreatic ductal adenocarcinoma and frequency of loss-of-function variants in gnomAD controls

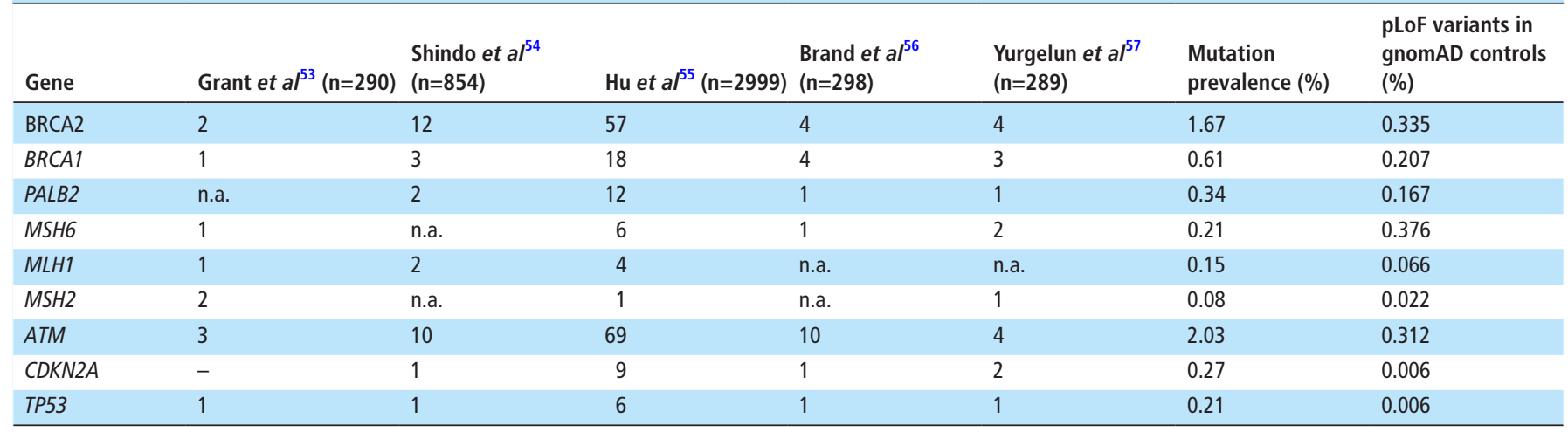

Germline mutations data were analysed from five sporadic PDAC cohorts (4730 samples).

gnomAD, Genome Aggregation Database; LoF, loss-of-function; n.a., not applicable. 
such concepts requires appropriate preclinical data in models that faithfully recapitulate human disease.

\section{TRANSLATIONAL MODELS OF DDR IN PANCREATIC CANCER}

Nowadays, the prediction of tumour biology and treatment response in patients is mainly based on DNA and RNAsequencing of the tumour. Here, subclonal genetic events require high coverage, and an incomplete characterisation of the mutational spectrum, for example, due to simplified panel sequencing, limits the interpretation of the results. To study the effects of DDR deficiency on pancreatic carcinogenesis and to test novel therapeutic strategies, in vivo and in vitro model systems with a high translational capacity have been developed. ${ }^{64}$ Thus, the greatest challenge is the recapitulation of the exceptionally high intertumoural and intratumoural heterogeneity in PDAC.

Human PDAC cells harbouring BRCA2, FANCC, FANCG gene mutations display in vitro hypersensitivity to DNA interstrand crosslinking agents (ICA) such as mitomycin $\mathrm{C}$ or cisplatin, which do, in fact, result in structural and chromosomal alterations following xenograft transplantation. ${ }^{65}$ These twodimensional cell monolayers have the advantage of easy propagation, access and replicability. However, artefacts due to culture methods and clonal selection, as well as the lack of microenvironmental tumour interactions, limit their value and can only be a basis for more complex models.

Accordingly, in a genetically engineered mouse model the loss of Brca2 does not propagate PDAC development but needs further drivers such as Trp53. However, in both situations more chromosomal instability is generated that sensitises to DNAdamaging agents. ${ }^{17}{ }^{66}$ Interestingly, oncogenic KRAS $^{\mathrm{G} 12 \mathrm{D}}$ in a BRCA2-deficient background promotes chromosomal instability and apoptosis, but inhibits tumour growth. However, loss of Palb2 and Brca1 in a Trp53, Kras ${ }^{G 12 D}$-mutated context (KPC) enhances genomic instability, decreases survival, but generates vulnerability to ICA and PARP inhibitors. ${ }^{67}$ Interestingly, these tumours also showed a genotype-specific immune cell infiltration pattern with $\mathrm{CD}^{+} \mathrm{T}$ cells, resulting in decreased tumour progression and improved survival, after treatment with an interleukin (IL)-6 and programmed death-ligand 1 (PD-L1) antibody. $^{68}$

Atm-deficient mice expressing oncogenic KRAS ${ }^{\mathrm{G} 12 \mathrm{D}}$ (AKC) showed accelerated dysplastic growth in the pancreas, epithelialto-mesenchymal transition and a highly metastatic phenotype (figure 3). ${ }^{69}$ AKC mice exhibit features of the unstable human PDAC subtype including chromosomal instability, deregulated DNA integrity checkpoints and aneuploidy. ${ }^{4170}$ Single targeting of either PARP1 or ATR in this model yielded moderate efficacy comparable to gemcitabine. ${ }^{70}$ Moreover, targeting of the remaining HR-associated ATR protein and NHEJ by DNA-PK inhibition led to a lethal accumulation of DNA damage. Likewise, adding an ATM inhibitor to PARP, ATR and DNA-PK inhibition in ATM-proficient PDAC cells virtually removes DDR. Preclinically, maintenance therapy with single PARP inhibitors can force the selection of aneuploid, highly aggressive, multidrug-resistant subclones. $^{71}$

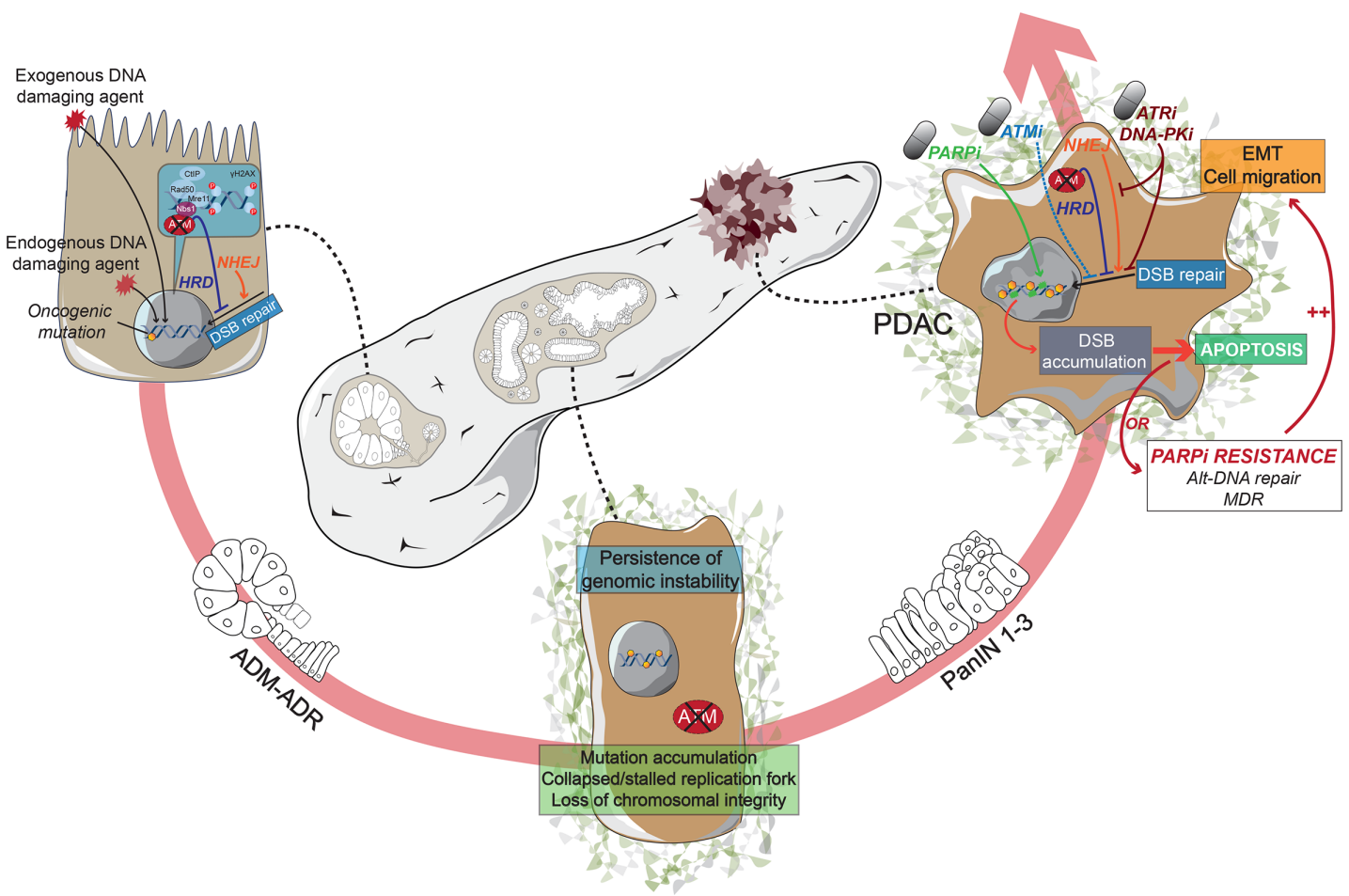

Figure 3 Schematic representation of pancreatic cancer progression in a homologous recombination-deficient context. HRDness resulting from ATM deficiency sensitises pancreatic cells to exogenous and endogenous DNA damaging factors enabling an oncogenic cascade through acinar-to-ductal metaplasia. Sustained impaired double-strand break repair results in accelerated genomic instability driving the progression of preneoplastic PanIN stages to HRD pancreatic ductal adenocarcinoma (PDAC). Persistent HRD or therapeutically induced HRD by eg, ATMi renders cancer cells vulnerable to therapeutic interventions promoting DNA damage. Monotherapeutic approaches as PARPi subsequently tend to complex multidrug resistance (MDR) involving epithelial-to-mesenchymal-transition (EMT) and alternative DNA repair. Smart tailored use of synergistically druggable vulnerabilities within the DNA damage repair machinery could be exploited to hit HRD tumors "hard and early" and prevent further MDR acquisition, as eg, recently shown upon inhibition of PARP, ATR and DNA-PKcs. ${ }^{71}$ ADM, acinar-to-ductal metaplasia; ADR, acinar-to-ductal reprogramming; DSB, double-strand break; HRD, homologous recombination-deficient; NHEJ, non-homologous end joining; PanIN, pancreatic intraepithelial neoplasia. 
Patient-derived xenografts (PDX) are today state of the art for the human translation of the aforementioned models ${ }^{72}$ and do, in fact, faithfully reflect phenotypic and therapeutic features. ${ }^{73}$ However, PDX are not suitable for either high-throughput drug screens or response prediction analysis in an individual patient due the long time required for their determination and propagation.

Therefore, three-dimensional cultured organoids can be easily determined from different sources including circulating tumour cells, ${ }^{74}$ metastasis or primary PDAC itself in a short time span. ${ }^{75}$ Patient-derived organoids (PDOs) represent PDAC heterogeneity and partly its microenvironment, ${ }^{75} 76$ providing a potentially better model system for testing/predicting drug response. ${ }^{77} 78$

\section{THERAPEUTIC INTERFERENCE WITH THE DDR IN PANCREATIC CANCER Platinum analogues}

Platinum agents can crosslink purine bases on the DNA, thereby interrupting DNA transcription and stall replication which can consecutively lead to DSBs and the induction of apoptosis. ${ }^{79}$ The removal of monoadducts on one DNA strand in response to platinum-induced DNA damage primarily involves NER. The repair of interstrand crosslinks additionally uses the FA pathway, translesion synthesis and HR, making these agents interesting for patients with an HRDness phenotype (figure 1). ${ }^{80}{ }^{81}$ It is of note that structural differences in platinum agents cause differences in DDR recognition as has been observed for cisplatin and oxaliplatin, although they form similar adducts at the same sites on the DNA. These differences in recognition, excision and processing affect the cytotoxicity and activity of the individual platinum adducts. ${ }^{82}$ Genomic instability in PDAC, at least in the case of BRCA1/2 or PALB2 mutations, co-segregates with (i) defective DNA maintenance, (ii) a mutational signature of DNA damage repair deficiency and (iii) an exceptional response to platinum. This may allow treatment stratification according to a given genetic event. ${ }^{16}$ Molecular subtyping is necessary for identifying these new target populations of unstable PDACs. The response of 820 patients with PDAC to a platinum-based regimen was recently evaluated in a large registry with a comprehensive genomic profiling programme. HRDness-causing germline or somatic mutations were grouped into three categories according to a known or suspected platinum responsiveness: (i) BRCA1/BRCA2/PALB2, (ii) ATM/ATR and (iii) FA core/MRN complex effectors. Overall, HR mutations were prevalent in $16.5 \%$ of patients. Interestingly, patients with advanced HR-defective (HRD) PDAC had a worse outcome than patients with HR-proficient (HRP) PDAC if they were not treated with platinum, underpinning their overall more aggressive tumour biology and particular platinum susceptibility (mOS: HRD 0.76 years vs HRP 1.13 years, $p=0.1535)$. In line platinum treatment substantially prolonged mOS in the HRD patients $(n=53)$ compared with the HRP patients $(n=258)$ (mOS: HRD 2.37 years vs HRP 1.45 years; $\mathrm{p}=0.000072$; HR, $0.44,95 \%$ CI 0.29 to 0.66 ). The mOS positively correlated with an increasing number of HR-related mutations and was independent of the therapy line. ${ }^{83}$ Golan et al collected data from 43 patients with advanced BRCA1/2-mutated PDAC, showing a significant survival benefit for platinum treatment compared with platinum-naïve patients (22 vs 9 months; $\mathrm{p}<0.039) .{ }^{84}$ Interestingly, in patients with FPC, platinum efficacy increases with the number of affected FDRs. ${ }^{85}$ A recent phase II trial further determined the effectivity of a first-line gemcitabine/cisplatin treatment in 50 patients with advanced gBRCA1/2, PALB2-mutated PDAC (2-year OS
$30.6 \%$ and 3-year OS 17.8\%). ${ }^{86}$ Various retrospective studies confirmed the superior tumour response to platinum derivates in DDR-deficient PDAC (summarised in table 3). ${ }^{848587}$ FOLFIRINOX is the only platinum-containing treatment for patients with advanced PDAC established in a positive phase III trial. ${ }^{8}$ However, only about $25 \%$ of patients are eligible for FOLFIRINOX, due to its high level of adverse effects. ${ }^{88}$ Therefore, appropriate patient selection, including the Eastern Cooperative Oncology Group performance status and the genetic make-up of the tumour, is similarly critical. A retrospective analysis of 32 curatively resected patients with a germline BRCA1, BRCA2 or PALB2 mutation revealed a significant survival benefit when treated with platinum, compared with $62 \mathrm{HRP}$ patients (mOS: HRD 47.7 months vs HRP 23.1 months, $\mathrm{p}=0.032$ ). Interestingly, the subgroup of HRD patients benefited to a relative extent from perioperative platinum-based chemotherapy (mOS: HRD not reached vs HRP 23.1 months). ${ }^{89}$ If platinum was omitted the survival rates were similar between both cohorts. Various other studies reported similar trends (summarised in table 4).

In view of the data shown above, several conclusions can be drawn: (i) in patients with unselected advanced PDAC the only approved platinum-based regimen in a first-line setting is FOLFIRINOX (level of evidence 1b); (ii) platinum does not seem to be the main critical effector in HR-proficient PDAC in either an adjuvant (level of evidence $1 \mathrm{a})^{90}$ or palliative setting (level of evidence $1 \mathrm{a})^{91}$; (iii) platinum derivates such as oxaliplatin seem to determine the treatment response to a combination regimen such as FOLFIRINOX in advanced HRD PDAC. ${ }^{39293}$

\section{PARP inhibitors}

PARPs are activated by DNA breaks and catalyse the transfer of ADP-riboses to form long-branched chains to target proteins involved in processes such as transcription and DNA damage repair. The resulting scaffold of negatively charged polymers further recruits DDR effectors (figure 1). PARP1 was originally described in SSB repair through base excision but is now wellaccepted as also participating in DSB repair, stalled replication fork sensing and in the recruitment of DNA repair proteins at DNA damage sites ${ }^{94}$ (figure 1). As PARP1/2 are crucial enzymes during HR-mediated DSB repair in most cancer cells, targeting these enzymes in HRD tumours seems to be an elegant method and underpins the principle of synthetic lethality. ${ }^{94}$ However, side effects in highly proliferative healthy cells can occur as well. PARP inhibitors are nicotinamide mimetics that directly inhibit PARP1 activity and further act by trapping the PARP protein at SSBs, forcing a lethal accumulation of DNA damage and cell death consecutively. While the efficacy of PARP1 inhibitors is established in BRCA-associated cancer types, ${ }^{37}$ their specific role in PDAC has only recently been demonstrated. However, monotherapy with PARP1 inhibitors displayed only modest activity in HRD PDAC, mostly BRCA1/2-mutated ${ }^{95-97}$ (table 5), and studies without genetic stratification did not show a meaningful benefit. ${ }^{98}$ Besides the missing stratification, factors such as previous therapies are meaningful, for example, as shown in a phase I trial in pretreated BRCA1/2-mutated patients with PDAC, in which only patients who were not refractory to platinum responded (PR or CR) to rucaparib. ${ }^{95}$ However, in proving the effectiveness of gemcitabine/cisplatin (as shown in 'Platinum analogues' section) in gBRCA/PALB2-mutated PDAC, a phase II trial failed to demonstrate an additional benefit of veliparib in 27 patients (mOS G/C +V 15.5 months vs G/C 16.4 months, $\mathrm{p}=0.6$ ) (table 5). ${ }^{86}$ In line with this, a currently not fully published phase $\mathrm{I} / \mathrm{II}$ trial in patients with advanced PDAC showed a significantly 
Recent advances in clinical practice

Table 3 Retrospective studies on platinum-based chemotherapy in patients with advanced homologous recombination-deficient PDAC

\begin{tabular}{|c|c|c|c|c|c|c|c|c|}
\hline Mutations & Design & $\begin{array}{l}\text { Therapy } \\
\text { line }\end{array}$ & Therapy & $\begin{array}{l}\text { Number } \\
\text { of pts. }\end{array}$ & mPFS & mOS & Efficacy & Reference \\
\hline $\begin{array}{l}\text { Group 1: BRCA1/2, PALB2 } \\
(\mathrm{n}=38) \\
\text { Group 2: } A T M I A T R I A T R X(\mathrm{n}=22) \\
\text { Group 3: BAP1, BARD1, BRIP1, } \\
\text { CHEK1/2, RAD50/51/51B, } \\
\text { FANCAICID2IEIFIG/L }(\mathrm{n}=12)\end{array}$ & Retrospective & Various & $\begin{array}{l}\text { Platinum-containing } \\
\text { any therapy line } \\
\text { Platinum-naïve }\end{array}$ & $\begin{array}{l}\text { Total: } 443 \\
\text { HRD: } 72 \\
\text { HRP: } 371\end{array}$ & $\begin{array}{l}\text { First-line: } \\
\text { HRD+platinum } \\
(n=53): 13.7 \mathrm{~m} \\
\text { HRP+platinum } \\
\text { ( } n=268): 8.2 \mathrm{~m} \\
\text { Second-line: } \\
\text { HRD+platinum } \\
\text { ( } n=28): 8.6 \mathrm{~m} \\
\text { HRP+platinum } \\
(n=103): 4.1 \mathrm{~m}\end{array}$ & $\begin{array}{l}\text { HRD+platinum } \\
(n=53): 2.37 y \\
\text { HRD-platinum } \\
(n=19): 0.76 y \\
\text { HRP+platinum } \\
(n=258): 1.45 y \\
\text { HRP-platinum } \\
\text { ( } n=113): 1.13 y\end{array}$ & $\begin{array}{l}\text { HRD+platinum: } \\
p=0.001\end{array}$ & 83 \\
\hline $\begin{array}{l}B R C A 1 \\
B R C A 2\end{array}$ & Retrospective & First-line & $\begin{array}{l}\text { Platinum-containing } \\
\text { any therapy line } \\
\text { Platinum-naïve }\end{array}$ & Total: 43 & n.a. & $\begin{array}{l}\text { HRD+platinum } \\
(n=22): 22 \mathrm{~m} \\
\text { HRD-platinum } \\
(\mathrm{n}=21): 9 \mathrm{~m}\end{array}$ & $p=0.0389$ & 84 \\
\hline $\begin{array}{l}\text { BRCA1 }(\mathrm{n}=7) \\
\text { BRCA2 }(\mathrm{n}=5) \\
\text { PALB2 }(\mathrm{n}=3) \\
\text { MSH2 }(\mathrm{n}=1) \\
\text { FANCF }(\mathrm{n}=1)\end{array}$ & Retrospective & First-line & FOLFIRINOX & $\begin{array}{l}\text { Total: } 36 \\
\text { HRD: } 12\end{array}$ & n.a. & $\begin{array}{l}\text { HRD: } 14 \mathrm{~m} \\
\text { HRP: } 5 \mathrm{~m}\end{array}$ & $\begin{array}{l}\text { HRD vs HRP: } \\
p=0.08\end{array}$ & 126 \\
\hline $\begin{array}{l}\text { BRCA2 }(\mathrm{n}=10) \\
\operatorname{ATM}(\mathrm{n}=8) \\
\text { BRCA1 }(\mathrm{n}=2) \\
\text { CHEK2 }(\mathrm{n}=2) \\
\text { ATR }(\mathrm{n}=1) \\
\text { PALB2 }(\mathrm{n}=1)\end{array}$ & Retrospective & Various & $\begin{array}{l}\text { Platinum-containing } \\
\text { any therapy line }\end{array}$ & $\begin{array}{l}\text { Total: } 28 \\
\text { HRD: } 13\end{array}$ & $\begin{array}{l}\text { HRD+platinum: } \\
20.8 \mathrm{~m} \\
\text { HRP+platinum: } \\
1.7 \mathrm{~m}\end{array}$ & n.a. & $p=0.049$ & 127 \\
\hline $\begin{array}{l}\text { gBRCA2 }(\mathrm{n}=3) \\
\text { BRCA2 }(\mathrm{n}=2) \\
\text { BRCA1 }(\mathrm{n}=1) \\
\text { POLE }(\mathrm{n} \\
\text { gRAD51C }(\mathrm{n}=1) \\
\text { gMUTYH }(\mathrm{n}=1)\end{array}$ & Retrospective & First-line & FOLFIRINOX & Total: 40 & $\begin{array}{l}\text { HRD+platinum: } \\
18.5 \mathrm{~m} \\
\mathrm{HRP}+\text { platinum: } \\
6.9 \mathrm{~m}\end{array}$ & $11.5 \mathrm{~m}$ & mPFS: $p=0.003$ & 128 \\
\hline $\begin{array}{l}\text { BRCA1 }(\mathrm{n}=5) \\
\text { BRCA2 }(\mathrm{n}=17) \\
\text { PALB2 }(\mathrm{n}=4)\end{array}$ & Retrospective & Various & $\begin{array}{l}\text { Platinum-containing } \\
\text { any therapy line }\end{array}$ & $\begin{array}{l}\text { Total: } 78 \\
\text { HRD: } 26 \\
\text { HRP: } 52\end{array}$ & $\begin{array}{l}\text { HRD+platinum: } \\
10.1 \mathrm{~m} \\
\text { HRP+platinum: } \\
6.9 \mathrm{~m}\end{array}$ & $\begin{array}{l}\text { HRD+platinum: } \\
24.6 \text { m } \\
\text { HRP+platinum: } \\
18.8 \text { m }\end{array}$ & $\begin{array}{l}\text { mPFS: } p=0.0068 \\
\text { mOS: } p=0.0467\end{array}$ & 129 \\
\hline
\end{tabular}

FOLFIRINOX, folinic acid, fluouracil, irinotecan, oxaliplatin; HRD, homologous recombination-deficient; HRP, homologous recombination-proficient; m, month; mOS, median overall survival; mPFS, median progression-free survival; n.a., not applicable; pts., patients; y, year.

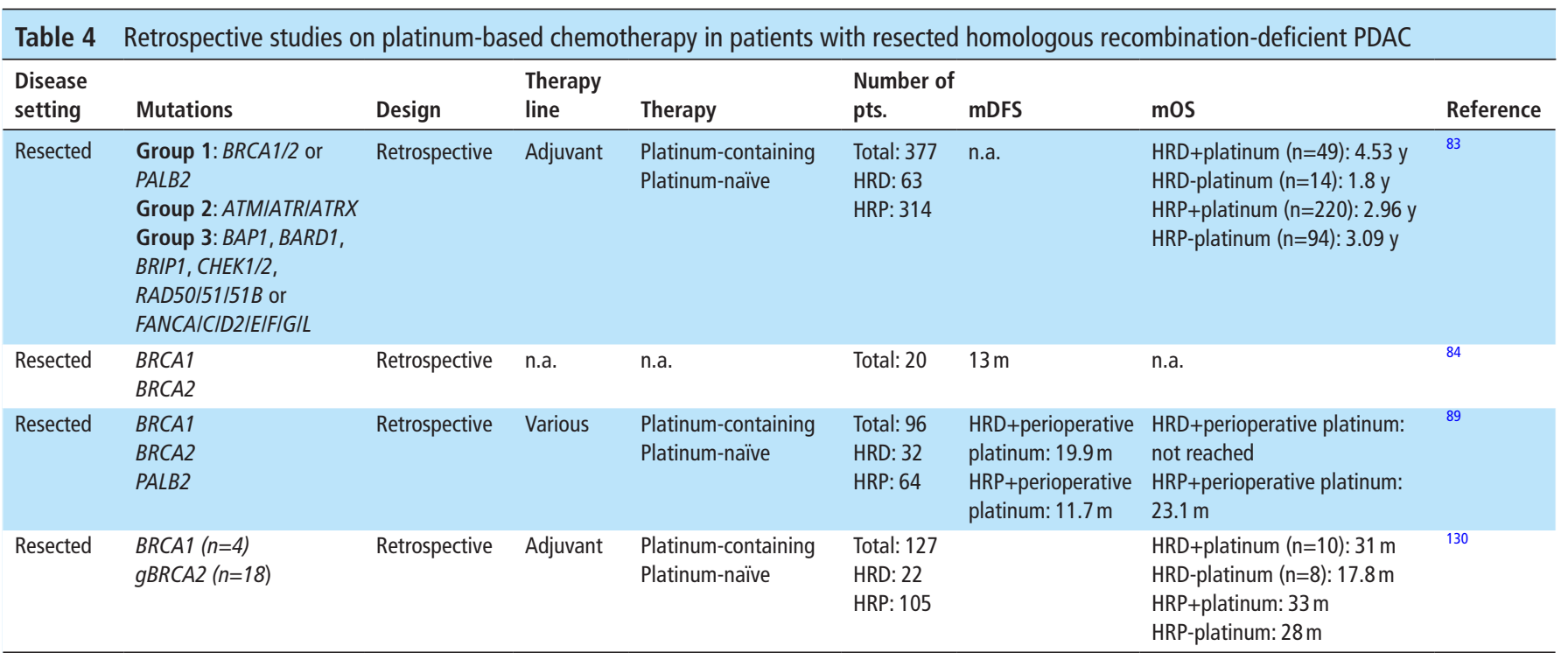

HRD, homologous recombination-deficient; HRP, homologous recombination-proficient; $m$, month; $n$.a., not applicable; pts., patients; $y$, year. 
Table 5 Clinical trials with PARP inhibitors on patients with advanced PDAC

\begin{tabular}{|c|c|c|c|c|c|c|c|c|c|}
\hline Mutations & Design & Therapy line & Therapy & Number of pts. & mPFS & $\mathrm{mOS}$ & Efficacy & Reference & $\begin{array}{l}\text { Abstract- } \\
\text { based } \\
\text { publication }\end{array}$ \\
\hline$g B R C A 1 / 2$ & Phase I & First-line & $\begin{array}{l}\text { Cisplatin } \\
\text { Gemcitabine } \\
\text { Veliparib }\end{array}$ & $\begin{array}{l}\text { Total: } 17 \\
\text { HRD: } 9 \\
\text { HRP: } 7 \\
\text { Unknown: } 1\end{array}$ & n.a. & $\begin{array}{l}\text { HRD: } 23.3 \mathrm{~m} \\
\text { HRP: } 11 \mathrm{~m}\end{array}$ & n.a. & 102 & No \\
\hline $\begin{array}{l}\text { gBRCA1 }(\mathrm{n}=12) \\
\text { gBRCA2 }(\mathrm{n}=35) \\
\text { gPALB2 }(\mathrm{n}=3)\end{array}$ & Phase II & First-line & $\begin{array}{l}\text { Cisplatin } \\
\text { Gemcitabine } \\
\text { A. +Veliparib } \\
\text { B. - Veliparib }\end{array}$ & $\begin{array}{l}\text { Total: } 50 \\
\text { A. } 27 \\
\text { B. } 23\end{array}$ & $\begin{array}{l}\text { A. } \quad 10.1 \mathrm{~m} \\
\text { B. } \quad 9.7 \mathrm{~m}\end{array}$ & $\begin{array}{l}\text { A. } 15.5 \mathrm{~m} \\
\text { B. } 16.4 \mathrm{~m}\end{array}$ & $\begin{array}{l}\text { mPFS: } \\
p=0.73 \\
\text { mOS: } p=0.6\end{array}$ & 86 & Yes \\
\hline $\begin{array}{l}g B R C A 1 / 2(\mathrm{n}=16) \\
s B R C A 1 / 2(\mathrm{n}=3)\end{array}$ & Phase II & $\geq$ Second-line & Rucaparib & Total: 19 & n.a. ${ }^{*}$ & n.a. * & n.a. ${ }^{*}$ & 95 & No \\
\hline $\begin{array}{l}\text { gBRCA1 }(\mathrm{n}=5) \\
g B R C A 2(\mathrm{n}=11)\end{array}$ & Phase II & $\geq$ Second-line & Veliparib & $\begin{array}{l}\text { Total: } 16 \\
\text { HRD: } 9 \\
\text { HRP: } 7\end{array}$ & $1.7 \mathrm{~m}$ & $3.1 \mathrm{~m}$ & n.a. & 97 & No \\
\hline $\begin{array}{l}\text { gBRCA1 }(\mathrm{n}=5) \\
\text { gBRCA2 }(\mathrm{n}=17) \\
\text { gBRCA1/2 }(\mathrm{n}=1)\end{array}$ & Phase II & $\geq$ Second-line & Olaparib & Total: 23 & $4.6 \mathrm{~m}$ & $9.8 \mathrm{~m}$ & n.a. & 96 & No \\
\hline $\begin{array}{l}\text { DDR mutation (eg, } \\
\text { BRCA1/2, PALB2, } \\
\text { ATM) }\end{array}$ & Phase I/II & Various & $\begin{array}{l}\text { mFOLFOX } \\
\text { Veliparib }\end{array}$ & $\begin{array}{l}\text { Total: } 57 \\
\text { HRD: } 16 \\
\text { HRP } 41\end{array}$ & $\begin{array}{l}\text { HRD: } 7.2 \mathrm{~m} \\
\text { HRP: } 3.5 \mathrm{~m}\end{array}$ & $\begin{array}{l}\text { HRD: } 11.1 \mathrm{~m} \\
\text { HRP: } 6.8 \mathrm{~m}\end{array}$ & n.a. & 99 & Yes \\
\hline $\begin{array}{l}\text { gBRCA1 }(\mathrm{n}=3) \\
\text { gBRCA2 }(\mathrm{n}=13) \\
\text { gPALB2 }(\mathrm{n}=2) \\
\text { sBRCA2 }(\mathrm{n}=1)\end{array}$ & Phase II & $\begin{array}{l}\text { First-line } \\
\text { maintenance } \\
\text { after platinum } \\
\text { induction }\end{array}$ & Rucaparib & Total: 19 & $9.1 \mathrm{~m}$ & n.a. & n.a. & 101 & Yes \\
\hline $\begin{array}{l}\text { gBRCA1 }(\mathrm{n}=45) \\
\text { gBRCA2 }(\mathrm{n}=108) \\
\text { gBRCA1/2 }(\mathrm{n}=1)\end{array}$ & Phase III & $\begin{array}{l}\text { First-line } \\
\text { maintenance } \\
\text { after platinum } \\
\text { induction }\end{array}$ & $\begin{array}{l}\text { A. Olaparib } \\
\text { B. Placebo }\end{array}$ & $\begin{array}{l}\text { Total: } 154 \\
\text { A. } 92 \\
\text { B. } 62\end{array}$ & $\begin{array}{l}\text { A. } \quad 7.4 \mathrm{~m} \\
\text { B. } \quad 3.8 \mathrm{~m}\end{array}$ & $\begin{array}{l}\text { A. } \quad 18.9 \mathrm{~m} \\
\text { B. } \quad 18.1 \mathrm{~m}\end{array}$ & $\begin{array}{l}\text { mPFS: } \\
p=0.004 \\
\text { mOS: } \\
p=0.91\end{array}$ & 100 & No \\
\hline
\end{tabular}

*As prespecified in the protocol, enrolment was stopped because of an insufficient response rate among the first 15 patients.

FOLFOX, folinic acid, fluouracil, oxaliplatin

; HRD, homologous recombination-deficient; HRP, homologous recombination-proficient; m, month; mOS, median overall survival; mPFS, median progression-free survival; n.a., not applicable; pts., patients.

higher objective response rate (ORR) of 50\% in HRD patients $(n=16)$ compared with 17\% HRP patients $(n=41)$ for the combination of folinic acid, fluouracil, oxaliplatin and veliparib (table 5) ${ }^{99}$ The most promising evidence of PARP inhibition in advanced PDAC was published recently from the phase III POLO trial. ${ }^{100}$ Patients with germline BRCA1/BRCA2-mutated advanced PDAC without progress to platinum-based first-line chemotherapy ( $\geq 16$ weeks) received either olaparib as maintenance treatment or placebo. Olaparib nearly doubled the median PFS compared with placebo (7.4 vs 3.8 months; $p=0.004)$, while OS remained similar in both arms (18.9 vs 18.1 months). ${ }^{100}$ The interim analysis of a single-arm phase II trial with rucaparib as maintenance therapy after platinum-based induction in the case of any pathogenic BRCA1, BRCA2 or PALB2 mutation also demonstrated an ORR of $37 \%$ with minimal toxicity in 19 patients. ${ }^{101}$ In summary, PARP inhibitors represent the first targeted therapy to show efficacy in a subpopulation of patients with advanced PDAC in a phase III clinical trial. ${ }^{100}$

\section{Toxicity and therapeutic pitfalls}

PARP inhibitors cause side effects as seen with high-dose veliparib, causing unacceptably high haematological toxicity and a sporadic association with acute myeloid leukaemia in the long term. ${ }^{102}$ Similarly, veliparib plus gemcitabine/cisplatin and olaparib plus cisplatin/irinotecan/mitomycin C were associated with a marked increase of mainly haematological Common Terminology Criteria for Adverse Events (CTCAE) $\geq$ grade 3 toxicities. ${ }^{103}$ Adverse events CTCAE $\geq$ grade 3 also emerged in $40 \%$ of patients on olaparib monotherapy, mainly involving haematological and GI side effects, as well as fatigue/asthenia. ${ }^{95} 96100$ However, health-related quality of life in the POLO trial revealed no clinically meaningful difference between the olaparib and placebo groups. ${ }^{104}$ Thus, the toxicity of PARP inhibitors has to be taken into account, particularly when combined with chemotherapy and when used at high doses. Although this has not been ultimately solved, there might be potential solutions for optimising these therapies, such as (i) more elaborated application regimens, (ii) novel drug formulations and/or (iii) the synergistic action of several drugs each used at an ineffective dose range on their own. So-called 'nanomedicine' strategies could help to overcome drug delivery challenges by reducing systemic toxicities on the one hand and by overcoming diffusion-limiting PDAC stroma on the other. As suggested by the approved nabPTX novel concepts with superior activity could arise, including surface-optimised nanocarriers. ${ }^{9} 105$

Another pitfall is the lack of predictive knowledge about a given HRDness-causing mutation, that is, not every mutation of a given DDR gene assigns sensitivity to PARP inhibitors. ${ }^{106}$ At the moment, most of the data collected on BRCA1/2 mutations and on non-BRCA mutations are purely preclinical ${ }^{70} 107$ (figure 2). In ovarian cancer, it has already been shown that both somatic genetic alterations and modifications in epigenetic markers may lead to functional restoration and revert HRD, but whether the same can happen in PDAC tumours is elusive. ${ }^{108} 109$ We need to develop better in silico prediction algorithms that take into account the general role of a gene in a signalling network and its precise mutation. Finally, the additive value of PARP inhibitors together with or after a platinum-based regimen is questionable and response predictors in this clinical setting are lacking. ${ }^{37}$ 95-97 100

Some open questions still remain and a multimodal approach including preclinical models, advanced in silico algorithms and explorative basket trials also including non-BRCA1/2 mutations is required. Here, it might be reasonable to restrict these to 
Recent advances in clinical practice

\begin{tabular}{|c|c|c|c|c|}
\hline Trial & Design & Patients & Treatment & Status \\
\hline NCT02950064 & Phase I trial, open-label & $\begin{array}{l}\text { BRCA-mutated pancreatic, ovarian, triple-negative breast or prostate } \\
\text { cancers or solid tumours with other DDR mutations }\end{array}$ & BTP-114, a novel platinum product & $\begin{array}{l}\text { Active, not } \\
\text { recruiting }\end{array}$ \\
\hline NCT01489865 & $\begin{array}{l}\text { Phase } 1 / l \text { trial, single } \\
\text { arm }\end{array}$ & $\begin{array}{l}\text { PDAC with } B R C A \text { mutation or personal or family history of hereditary } \\
\text { breast or ovarian cancer }\end{array}$ & $\begin{array}{l}\text { ABT-888 (a new PARP inhibitor) with } \\
\text { mFOLFOX6 }\end{array}$ & $\begin{array}{l}\text { Active, not } \\
\text { recruiting }\end{array}$ \\
\hline NCT01585805 & $\begin{array}{l}\text { Phase II, open-label, } \\
\text { randomised }\end{array}$ & Metastatic or locally advanced $B R C A$-mutated PDAC & $\begin{array}{l}\text { Veliparib alone vs gemcitabine/cisplatin vs } \\
\text { veliparib and gemcitabine/cisplatin }\end{array}$ & $\begin{array}{l}\text { Active, not } \\
\text { recruiting }\end{array}$ \\
\hline NCT02498613 & $\begin{array}{l}\text { Phase II trial, single } \\
\text { arm }\end{array}$ & $\begin{array}{l}\text { Advanced solid tumours with failure to at least one line of standard } \\
\text { systemic treatment }\end{array}$ & Olaparib+cediranib (anti-VEGF) & Recruiting \\
\hline NCT03162627 & Phase I/II & Refractory advanced cancer & Olaparib+selumetinib (anti-MEK) & Recruiting \\
\hline NCT03404960 & $\begin{array}{l}\text { Phase Ib/ll, open-label, } \\
\text { randomised }\end{array}$ & $\begin{array}{l}\text { Metastatic or locally advanced PDAC, with } 16 \text { weeks of platinum- } \\
\text { based treatment without progression }\end{array}$ & Niraparib+nivolumab or ipilimumab & Recruiting \\
\hline NCT02630199 & Phase I, open-label & Advanced, refractory cancer & Paclitaxel and AZD6738 (ATR inhibitor) & Recruiting \\
\hline NCT02223923 & Phase I, single group & Solid tumour refractory to conventional treatment & AZD6738 (ATR inhibitor) with radiotherapy & Recruiting \\
\hline NCT03669601 & $\begin{array}{l}\text { Phase I, non- } \\
\text { randomised }\end{array}$ & $\begin{array}{l}\text { Locally advanced or metastatic solid tumour that has progressed on } \\
\text { standard therapy }\end{array}$ & AZD6738 and gemcitabine & Recruiting \\
\hline NCT02264678 & $\begin{array}{l}\text { Phase I, two-part, } \\
\text { open-label }\end{array}$ & $\begin{array}{l}\text { Solid malignant tumour that is not considered appropriate for further } \\
\text { standard treatment }\end{array}$ & $\begin{array}{l}\text { AZD6738 with different drugs, including } \\
\text { carboplatin and olaparib }\end{array}$ & Recruiting \\
\hline NCT03682289 & Phase II & $\begin{array}{l}\text { Locally advanced or metastatic solid tumour malignancy, including any } \\
\text { pancreatic cancers }\end{array}$ & $\begin{array}{l}\text { AZD } 6738 \text { alone or in combination with } \\
\text { olaparib }\end{array}$ & Recruiting \\
\hline NCT02576444 & Phase II & Metastatic progressive cancer & $\begin{array}{l}\text { Patients with HRD will be treated with olaparib } \\
\text { and AZD6738 }\end{array}$ & $\begin{array}{l}\text { Active, not } \\
\text { recruiting }\end{array}$ \\
\hline NCT02723864 & Phase I, single group & Metastatic cancer with previous fail to survival prolonging therapies & Veliparib+cisplatin+VX-970 (ATR inhibitor) & Recruiting \\
\hline NCT02595931 & Phase I, single group & $\begin{array}{l}\text { Metastatic or unresectable malignancy that is refractory to standard } \\
\text { therapy or for which no standard therapy exists and where irinotecan } \\
\text { is deemed a reasonable treatment option }\end{array}$ & VX-970 and irinotecan & Recruiting \\
\hline NCT02588105 & Phase I & $\begin{array}{l}\text { Locally advanced/metastatic cancer that is refractory or resistant to } \\
\text { standard therapy, or have no effective standard }\end{array}$ & $\begin{array}{l}\text { AZD0156+olaparib, AZD0156+irinotecan/ } \\
\text { FOLFIRI }\end{array}$ & $\begin{array}{l}\text { Active, not } \\
\text { recruiting }\end{array}$ \\
\hline NCT02194829 & Phase I & $\begin{array}{l}\text { A phase I and randomised phase II study of nab-paclitaxel/gemcitabine } \\
\text { with or without AZD1775 for treatment of metastatic adenocarcinoma } \\
\text { of the pancreas }\end{array}$ & $\begin{array}{l}\text { Nab-paclitaxel/gemcitabine } \\
\text { Nab-paclitaxel/gemcitabine+AZD1775 }\end{array}$ & $\begin{array}{l}\text { Active, not } \\
\text { recruiting }\end{array}$ \\
\hline
\end{tabular}

FOLFIRI, folinic acid, fluouracil, irinotecan

; FOLFOX, folinic acid, fluouracil, oxaliplatin

; nab, nanosized albumin-bound; PDAC, pancreatic ductal adenocarcinoma

BRCA-associated cancers, as in non-BRCA-associated cancers at least $B R C A 1 / 2$ mutations frequently appear to work in a biologically neutral manner. ${ }^{37}$

\section{Inducing homologous recombination deficiency and future directions}

New treatment modalities currently aim at inducing or maintaining an HRD state independent of the mutational make-up of a given tumour. This could increase the efficacy of DDRinterfering agents and increase the patient cohort. Such strategies might also bypass drug resistance, since PARP inhibitor resistance can occur, for example, by HR restoration (figure 3 ). Specifically, hypoxia might impair HR, for instance, by silencing the BRCA1 promoter or downregulation of RAD51/52. ${ }^{110}$ Antiangiogenic agents (AA) counteract hypoxia-induced angiogenesis and, in turn, lower blood perfusion and thereby oxygen tension. This hypothesis is in contrast with transiently AA-induced repair termed tumour 'vessel normalisation'. Nevertheless, concrete evidence supporting the fact that vessel normalisation is decisive for AA functioning is lacking, whereas induced hypoxia appears to be the major driver. ${ }^{111}$ Indeed, trials testing bevacizumab and cediranib combined with olaparib did not show unexpected toxicities, but showed promising antitumour response at least in ovarian cancer. ${ }^{94}$ Phase II basket trials including PDAC are currently recruiting (NCT02498613; table 6).
The phosphoinositide 3-kinase (PI3K)-protein kinase B-mammalian target of rapamycin pathway seems relevant in maintaining $\mathrm{HR},{ }^{94}$ thereby blocking PI3K sensitising to PARP inhibitors via BRCA1/2 downregulation in triple-negative breast cancer cells. ${ }^{112}$ However, robust data are lacking and clinical evidence only supports tolerability. ${ }^{113}$ MEK inhibition causes repression of both HR and NHEJ repair activity in PDAC cells. A clinical trial exploring these preclinical data is currently enrolling (NCT03162627; table 6). Furthermore, inhibition of the nuclear serine/threonine kinase WEE1 can induce HRDness in PDAC. The DNA damage checkpoint WEE1 impairs unscheduled replication origin firing and thus prevents nucleotide pool depletion and replication stress, ultimately resulting in DSBs. ${ }^{114}$ Preclinically, the WEE1 inhibitor AZD1775 sensitises to radiotherapy, an observation currently examined in a clinical trial (NCT02194829; table 6). Another approach might be molecules mimicking BRCA2 mutations that disrupt the RAD51-BRCA2 complex. ${ }^{115}$ Finally, clinical grade ATM inhibitors (AZD0156, KU60019, AZD1390), which directly prevent downstream ATM phosphorylation, can sensitise tumour cells to DDR interfering strategies. Preliminary data from the AToM study, a phase I clinical trial in advanced cancers, showed promising partial responses on a combination with olaparib. ${ }^{116}$

The limited success of treatments based on single DDR inhibiting agents is mostly due to compensatory pathways, drug toxicity and a lack of reliable response predictors. Moreover, 
the appropriate stratification of clinical trials for the different DDR alterations may help to identify the best treatment, as it has already done in prostate cancer (eg, Triton2 study, NCT02952534). Exploiting vulnerabilities by (i) seeking a synthetic lethal interaction within a given PDAC genotype and/ or by (ii) a synergistic interaction in the low-dose range between applied drugs could boost both efficacy and tolerability ${ }^{71}$ Thus, the multiple targeting of distinct DDR pathways could be a promising concept, provided that precise dose-escalation studies are warranted together with extensive preclinical testing. The combinatorial use of ATR inhibitors with conventional chemotherapy or PARP inhibitors in patients with ATM-deficient PDAC seems interesting, as it could assign HRDness to a given cancer. ${ }^{107}$ This is currently being assessed in various recruiting trials; for more details see table 6 .

PDOs may in future also provide guidance for selecting the most appropriate combination(s). A prerequisite for such an approach, particularly in a disease like PDAC with extraordinary high intertumoural heterogeneity, is the sequencing of the tumour or the tumour DNA in liquid biopsies to determine the presence of a particular DDR mutation that can be appropriately targeted.

\section{Homologous recombination deficiency and immunotherapy}

Checkpoint inhibitors have revolutionised the treatment of some cancers, with the highest efficacy in mismatch repairdeficient tumours carrying a significant mutational burden. As mentioned above, MMR proteins correct the erroneous incorporation of bases during DNA replication. In PDAC, MMR deficiency is very rarely found in around $1 \%$ of cases and is associated with a better prognosis. ${ }^{117}$ MMR deficiency is predictive of an improved response to immunotherapy across multiple types of cancer including PDACs. ${ }^{118}$ PARP inhibitors can increase immune response and induce PD-L1 expression. ${ }^{117}$ Nonetheless, whether this establishes a synergistic axis between PARP and immune checkpoint inhibition in HRD PDAC remains unclear. In patients with PDAC, low ATM expression inversely correlates with PD-L1 expression, and the preclinical inhibition of ATM increased interferon signalling and sensitised to immune checkpoint inhibition. ${ }^{119} \mathrm{~A}$ phase $\mathrm{Ib} / \mathrm{II}$ trial is currently recruiting to estimate the efficacy and safety of PARP inhibition with either ipilimumab (anticytotoxic T-lymphocyte-associated protein 4) or nivolumab (antiprogrammed cell death protein 1) (table 6; NCT03404960). Supporting data come from phase II trials combining olaparib with durvalumab (anti-PD-L1), showing tolerable toxicity and promising disease control rates in patients with breast and prostate cancer. ${ }^{120}{ }^{121}$ In general, immunotherapy in PDAC appears to be restricted to cases with specific mutations leading to neoantigen expression. As in an unselected population with metastatic PDAC, ORR was far below expectations. ${ }^{122}$

\section{CONCLUSIONS}

Impaired DNA damage repair is a relevant characteristic of PDAC, frequently with an inherited origin. Loss-of-function mutations in genes involved in DNA damage repair justify therapeutic targeting with a platinum agent in the polychemotherapy and/or PARP inhibitors as a reasonable option, particularly for later lines of treatment. At least for BRCA-associated cancer types (pancreatic, prostate, breast or ovarian cancer), BRCA1/2 mutations remain clinically relevant, independent of their pathogenic or somatic origin. Maintenance with PARP inhibitors after induction chemotherapy is a promising approach that is likely to be incorporated in clinical practice for patients with a BRCA1/2 germline mutation. With the ultimate goal of hitting PDACs 'hard and early' and avoiding the emergence of resistant clones, more studies are urgently needed to demonstrate the efficacy of combinatorial approaches to DDR inhibition and to identify the best combinations for the respective targets in the DDR machinery. Furthermore, potential 'HRDness inducers' creating artificial vulnerabilities, in combination with DNA-damaging drugs such as PARP inhibitors and/or alternative DDR inhibitors, could provide a significant benefit for a larger group of patients with PDAC and open up a new era in the field of PDAC treatment.

Correction notice This article has been corrected since it published Online First. The joint author statement has been added.

Acknowledgements We are deeply grateful to Kuhn Elektro-Technik GmbH for supporting our research to fight pancreatic cancer. The authors thank Sabine Geller from the Media and Design department of the University of Ulm for her support in illustration editing.

Contributors All authors wrote and revised the manuscript.

Funding The authors disclosed receipt of the following financial support for the research, authorship and/or publication of this article: main funding was provided by the German Cancer Aid grant to AK (111879). Additional funding came from the Deutsche Forschungsgemeinschaft (DFG, KL 2544/1-1, 1-2, 5-1, 7-1), the BIU fund (Böhringer Ingelheim), the INDIMED-Verbund PancChip and the Else-KrönerFresenius Memorial funding to AK. AK also received funding from the DFG within the Heisenberg programme (KL2544/6-1) and from the Baden-Württemberg Foundation via ExPo Chip. ANR-DFG collaborative research project (ANR-18-CE92-0031, DFG KL 2544/5-1) to AK. AK, LW, TS were funded by the DFG HEIST RTG GRK 2254/1. LP was funded by Bausteinprogramm of Ulm University Hospital. LW was further supported by the German Cancer Aid Priority Program Translational Oncology (70112504)

\section{Competing interests None declared.}

Patient consent for publication Not required.

Provenance and peer review Commissioned; externally peer reviewed.

Open access This is an open access article distributed in accordance with the Creative Commons Attribution Non Commercial (CC BY-NC 4.0) license, which permits others to distribute, remix, adapt, build upon this work non-commercially, and license their derivative works on different terms, provided the original work is properly cited, appropriate credit is given, any changes made indicated, and the use is non-commercial. See: http://creativecommons.org/licenses/by-nc/4.0/.

\section{ORCID iDs}

Lukas Perkhofer http://orcid.org/0000-0003-0484-0974

Johann Gout http://orcid.org/0000-0003-0522-9800

Elodie Roger http://orcid.org/0000-0002-4930-6292

Alexander Kleger http://orcid.org/0000-0003-0592-5232

\section{REFERENCES}

1 Seufferlein T, Mayerle J. Pancreatic cancer in 2015: Precision medicine in pancreatic cancer--fact or fiction? Nat Rev Gastroenterol Hepatol 2016;13:74-5.

2 Ferreira RMM, Sancho R, Messal HA, et al. Duct- and Acinar-Derived pancreatic ductal adenocarcinomas show distinct tumor progression and marker expression. Cell Rep 2017;21:966-78.

3 Ryan DP, Hong TS, Bardeesy N. Pancreatic adenocarcinoma. N Engl J Med 2014;371:1039-49.

4 Barati Bagherabad M, Afzaljavan F, ShahidSales S, et al. Targeted therapies in pancreatic cancer: promises and failures. J Cell Biochem 2019;120:2726-41.

5 Neoptolemos JP, Palmer DH, Ghaneh P, et al. Comparison of adjuvant gemcitabine and capecitabine with gemcitabine monotherapy in patients with resected pancreatic cancer (ESPAC-4): a multicentre, open-label, randomised, phase 3 trial. The Lancet 2017;389:1011-24.

6 Conroy T, Hammel P, Hebbar M, et al. Folfirinox or gemcitabine as adjuvant therapy for pancreatic cancer. N Engl J Med 2018;379:2395-406

7 Murphy JE, Wo JY, Ryan DP, et al. Total neoadjuvant therapy with Folfirinox in combination with losartan followed by chemoradiotherapy for locally advanced pancreatic cancer: a phase 2 clinical trial. JAMA Oncol 2019;5:1020-7.

8 Conroy $T$, Desseigne $F$, Ychou $M$, et al. Folfirinox versus gemcitabine for metastatic pancreatic cancer. N Engl J Med 2011;364:1817-25.

9 Von Hoff DD, Ervin T, Arena FP, et al. Increased survival in pancreatic cancer with nab-paclitaxel plus gemcitabine. N Engl J Med 2013;369:1691-703. 
10 Moore MJ, Goldstein D, Hamm J, et al. Erlotinib plus gemcitabine compared with gemcitabine alone in patients with advanced pancreatic cancer: a phase III trial of the National cancer Institute of Canada clinical Trials Group. JCO 2007;25:1960-6.

11 Kindler HL, Niedzwiecki D, Hollis D, et al. Gemcitabine plus bevacizumab compared with gemcitabine plus placebo in patients with advanced pancreatic cancer: phase III trial of the cancer and leukemia group B (CALGB 80303). JCO 2010;28:3617-22.

12 Kindler HL, loka T, Richel DJ, et al. Axitinib plus gemcitabine versus placebo plus gemcitabine in patients with advanced pancreatic adenocarcinoma: a double-blind randomised phase 3 study. Lancet Oncol 2011;12:256-62.

13 Gonçalves A, Gilabert M, François E, et al. BAYPAN study: a double-blind phase III randomized trial comparing gemcitabine plus sorafenib and gemcitabine plus placebo in patients with advanced pancreatic cancer. Ann Oncol 2012;23:2799-805

14 Canon J, Rex K, Saiki AY, et al. The clinical KRAS(G12C) inhibitor AMG 510 drives anti-tumour immunity. Nature 2019:575:217-23.

15 Mueller $S$, Engleitner T, Maresch R, et al. Evolutionary routes and KRAS dosage define pancreatic cancer phenotypes. Nature 2018:554:62-8.

16 Waddell N, Pajic M, Patch A-M, et al. Whole genomes redefine the mutationa landscape of pancreatic cancer. Nature 2015:518:495-501.

17 Rowley M, Ohashi A, Mondal G, et al. Inactivation of BRCA2 promotes Trp53associated but inhibits KrasG12D-dependent pancreatic cancer development in mice. Gastroenterology 2011;140:1303-13.

18 Collisson EA, Sadanandam A, Olson P, et al. Subtypes of pancreatic ductal adenocarcinoma and their differing responses to therapy. Nat Med 2011;17:500-3.

19 Moffitt RA, Marayati R, Flate EL, et al. Virtual microdissection identifies distinct tumor- and stroma-specific subtypes of pancreatic ductal adenocarcinoma. Nat Genet 2015;47:1168-78.

20 Bailey P, Chang DK, Nones K, et al. Genomic analyses identify molecular subtypes of pancreatic cancer. Nature 2016;531:47-52.

21 Chan-Seng-Yue M, Kim JC, Wilson GW, et al. Transcription phenotypes of pancreatic cancer are driven by genomic events during tumor evolution. Nat Genet 2020;52:231-40.

22 Roberts NJ, Norris AL, Petersen GM, et al. Whole genome sequencing defines the genetic heterogeneity of familial pancreatic cancer. Cancer Discov 2016;6:166-75.

23 Negrini S, Gorgoulis VG, Halazonetis TD. Genomic instability-an evolving hallmark of cancer. Nat Rev Mol Cell Biol 2010;11:220-8.

24 Li Z, Pearlman AH, Hsieh P. Dna mismatch repair and the DNA damage response. DNA Repair 2016;38:94-101.

25 Marteijn JA, Lans $\mathrm{H}$, Vermeulen W, et al. Understanding nucleotide excision repair and its roles in cancer and ageing. Nat Rev Mol Cell Biol 2014;15:465-81.

26 Keijzers G, Bakula D, Scheibye-Knudsen M. Monogenic diseases of DNA repair. $N$ Engl J Med Overseas Ed 2017;377:1868-76.

27 Jasin M, Rothstein R. Repair of strand breaks by homologous recombination. Cold Spring Harb Perspect Biol 2013;5:a012740.

28 Zha S, Boboila C, Alt FW. Mre11: roles in DNA repair beyond homologous recombination. Nat Struct Mol Biol 2009;16:798-800.

29 Lamarche BJ, Orazio NI, Weitzman MD. The MRN complex in double-strand break repair and telomere maintenance. FEBS Lett 2010;584:3682-95.

30 Stolz A, Ertych N, Bastians H. Tumor suppressor Chk2: regulator of DNA damage response and mediator of chromosomal stability. Clin Cancer Res 2011;17:401-5.

31 Brown JS, O'Carrigan B, Jackson SP, et al. Targeting DNA repair in cancer: beyond PARP inhibitors. Cancer Discov 2017;7:20-37.

32 D'Andrea AD, Grompe M. The Fanconi anaemia/BRCA pathway. Nat Rev Cancer 2003:3:23-34.

33 Bhattacharyya A, Ear US, Koller BH, et al. The Breast Cancer Susceptibility Gene BRCA1 Is Required for Subnuclear Assembly of Rad51 and Survival following Treatment with the DNA Cross-linking Agent Cisplatin. J Bio/ Chem 2000;275:23899-903.

34 De Silva IU, McHugh PJ, Clingen PH, et al. Defining the roles of nucleotide excision repair and recombination in the repair of DNA interstrand cross-links in mammalian cells. Mol Cell Biol 2000;20:7980-90.

35 Zhao D, DePinho RA. Synthetic essentiality: targeting tumor suppressor deficiencies in cancer. Bioessays 2017;39. doi:10.1002/bies.201700076

36 Bray F, Ferlay J, Soerjomataram I, et al. GLOBOCAN estimates of incidence and mortality worldwide for 36 cancers in 185 countries. CA Cancer J Clin 2018;2018:394-424.

37 Jonsson P, Bandlamudi C, Cheng ML, et al. Tumour lineage shapes BRCA-mediated phenotypes. Nature 2019;571:576-9.

38 Notta F, Chan-Seng-Yue M, Lemire M, et al. A renewed model of pancreatic cancer evolution based on genomic rearrangement patterns. Nature 2016;538:378-82.

39 Jones $S$, Zhang $X$, Parsons DW, et al. Core signaling pathways in human pancreatic cancers revealed by global genomic analyses. Science 2008:321:1801-6.

40 Lord CJ, Ashworth A. Brcaness revisited. Nat Rev Cancer 2016;16:110-20.

41 Russell R, Perkhofer L, Liebau S, et al. Loss of ATM accelerates pancreatic cancer formation and epithelial-mesenchymal transition. Nat Commun 2015;6:7677.

42 Skaro M, Nanda N, Gauthier C, et al. Prevalence of germline mutations associated with cancer risk in patients with intraductal papillary mucinous neoplasms. Gastroenterology 2019;156:1905-13.
43 Klein AP, Brune KA, Petersen GM, et al. Prospective risk of pancreatic cancer in familial pancreatic cancer kindreds. Cancer Res 2004;64:2634-8.

44 Zhen DB, Rabe KG, Gallinger S, et al. Brca1, BRCA2, PALB2, and CDKN2A mutations in familial pancreatic cancer: a PACGENE study. Genet Med 2015;17:569-77.

45 Takai E, Yachida S, Shimizu K, et al. Germline mutations in Japanese familial pancreatic cancer patients. Oncotarget 2016;7:74227-35.

46 Nicolosi P, Ledet E, Yang S, et al. Prevalence of germline variants in prostate cancer and implications for current genetic testing guidelines. JAMA Oncol 2019;5:523-8.

47 Kobayashi H, Ohno S, Sasaki Y, et al. Hereditary breast and ovarian cancer susceptibility genes (review). Oncol Rep 2013;30:1019-29.

48 Greer JB, Whitcomb DC, Brand RE. Genetic predisposition to pancreatic cancer: a brief review. Am J Gastroenterol 2007;102:2564-9.

49 Ferrone CR, Levine DA, Tang LH, et al. BRCA Germline Mutations in Jewish Patients With Pancreatic Adenocarcinoma. JCO 2009;27:433-8

50 Murphy KM, Brune KA, Griffin C, et al. Evaluation of candidate genes MAP2K4, MADH4, ACVR1B, and BRCA2 in familial pancreatic cancer: deleterious BRCA2 mutations in 17\%. Cancer Res 2002:62:3789-93.

51 Sato N, Rosty C, Jansen M, et al. STK11/LKB1 Peutz-Jeghers gene inactivation in intraductal papillary-mucinous neoplasms of the pancreas. Am J Pathol 2001;159:2017-22.

52 Zhan W, Shelton CA, Greer PJ, et al. Germline variants and risk for pancreatic cancer: a systematic review and emerging concepts. Pancreas 2018;47:924-36.

53 Grant RC, Selander I, Connor AA, et al. Prevalence of germline mutations in cancer predisposition genes in patients with pancreatic cancer. Gastroenterology 2015;148:556-64.

54 Shindo K, Yu J, Suenaga M, et al. Deleterious germline mutations in patients with apparently sporadic pancreatic adenocarcinoma. JCO 2017;35:3382-90.

$55 \mathrm{Hu}$ C, Hart SN, Polley EC, et al. Association between inherited germline mutations in cancer predisposition genes and risk of pancreatic cancer. JAMA 2018;319:2401-9.

56 Brand R, Borazanci $E$, Speare $V$, et al. Prospective study of germline genetic testing in incident cases of pancreatic adenocarcinoma. Cancer 2018;124:3520-7.

57 Yurgelun MB, Chittenden AB, Morales-Oyarvide V, et al. Germline cancer susceptibility gene variants, somatic second hits, and survival outcomes in patients with resected pancreatic cancer. Genet Med 2019;21:213-23.

58 Geoffroy-Perez B, Janin N, Ossian K, et al. Cancer risk in heterozygotes for ataxiatelangiectasia. Int J Cancer 2001;93:288-93.

$59 \mathrm{Hu}$ C, Hart SN, Bamlet WR, et al. Prevalence of pathogenic mutations in cancer predisposition genes among pancreatic cancer patients. Cancer Epidemio Biomarkers Prev 2016:25:207-11.

60 Holter S, Borgida A, Dodd A, et al. Germline BRCA Mutations in a Large Clinic-Based Cohort of Patients With Pancreatic Adenocarcinoma. JCO 2015:33:3124-9.

61 Antoniou AC, Casadei S, Heikkinen T, et al. Breast-Cancer Risk in Families with Mutations in PALB2. N Engl J Med Overseas Ed 2014;371:497-506.

62 Reid S, Schindler D, Hanenberg H, et al. Biallelic mutations in PALB2 cause Fanconi anemia subtype FA-N and predispose to childhood cancer. Nat Genet 2007:39:162-4.

63 Turner N, Tutt A, Ashworth A. Hallmarks of 'BRCAness' in sporadic cancers. Nat Rev Cancer 2004:4:814-9.

64 Perkhofer L, Frappart P-O, Müller M, et al. Importance of organoids for personalized medicine. Per Med 2018;15:461-5.

65 van der Heijden MS, Brody JR, Dezentje DA, et al. In vivo therapeutic responses contingent on Fanconi anemia/BRCA2 status of the tumor. Clin Cancer Res 2005:11:7508-15.

66 Skoulidis F, Cassidy LD, Pisupati V, et al. Germline BRCA2 heterozygosity promotes KrasG12D -driven carcinogenesis in a murine model of familial pancreatic cancer. Cancer Cell 2010;18:499-509.

67 Park D, Shakya R, Koivisto C, et al. Murine models for familial pancreatic cancer: histopathology, latency and drug sensitivity among cancers of PALB2, BRCA1 and BRCA2 mutant mouse strains. PLoS One 2019;14:e0226714.

68 Mace TA, Shakya R, Pitarresi JR, et al. II-6 and PD-L1 antibody blockade combination therapy reduces tumour progression in murine models of pancreatic cancer. Gut 2018:67:320-32.

69 Drosos Y, Escobar D, Chiang MY, et al. ATM-deficiency increases genomic instability and metastatic potential in a mouse model of pancreatic cancer. Sci Rep 2017:7:11144

70 Perkhofer L, Schmitt A, Romero Carrasco MC, et al. Atm deficiency generating genomic instability sensitizes pancreatic ductal adenocarcinoma cells to therapyinduced DNA damage. Cancer Res 2017:77:5576-90.

71 Gout J, Perkhofer L, Morawe M, et al. Synergistic targeting and resistance to PARP inhibition in DNA damage repair-deficient pancreatic cancer. Gut 2020:1-18.

72 Morton CL, Houghton PJ. Establishment of human tumor xenografts in immunodeficient mice. Nature protocols 2007;2:247-50.

73 Rubio-Viqueira $B$, Jimeno $A$, Cusatis $G$, et al. An in vivo platform for translational drug development in pancreatic cancer. Clinical Cancer Research 2006;12:4652-61.

74 Gao D, Vela I, Sboner A, et al. Organoid cultures derived from patients with advanced prostate cancer. Cell 2014;159:176-87.

75 Tiriac $H$, Belleau $P$, Engle DD, et al. Organoid profiling identifies common responders to chemotherapy in pancreatic cancer. Cancer Discov 2018;8:1112-29. 
76 Vlachogiannis G, Hedayat S, Vatsiou A, et al. Patient-Derived organoids model treatment response of metastatic gastrointestinal cancers. Science 2018;359:920-6.

77 Huang L, Holtzinger A, Jagan I, et al. Ductal pancreatic cancer modeling and drug screening using human pluripotent stem cell- and patient-derived tumor organoids. Nat Med 2015;21:1364-71.

78 Wills ES, Drenth JPH. Building pancreatic organoids to aid drug development. Gut 2017;66:393-4.

79 Johnstone TC, Park GY, Lippard SJ. Understanding and improving platinum anticancer drugs-phenanthriplatin. Anticancer research 2014;34:471-6.

80 Semlow DR, Zhang J, Budzowska M, et al. Replication-Dependent unhooking of DNA interstrand cross-links by the NEIL3 glycosylase. Cell 2016;167:498-511.

81 Bhattacharjee S, Nandi S. Dna damage response and cancer therapeutics through the lens of the Fanconi anemia DNA repair pathway. Cell Commun Signal 2017;15:41.

82 Chaney SG, Campbell SL, Bassett E, et al. Recognition and processing of cisplatinand oxaliplatin-DNA adducts. Crit Rev Oncol Hematol 2005;53:3-11.

83 Pishvaian MJ, Blais EM, Brody JR, et al. Outcomes in patients with pancreatic adenocarcinoma with genetic mutations in DNA damage response pathways: results from the know your tumor program. JCO Precis Oncol 2019:1-10.

84 Golan T, Kanji ZS, Epelbaum R, et al. Overall survival and clinical characteristics of pancreatic cancer in BRCA mutation carriers. Br J Cancer 2014;111:1132-8.

85 Fogelman D, Sugar EA, Oliver G, et al. Family history as a marker of platinum sensitivity in pancreatic adenocarcinoma. Cancer Chemother Pharmacol 2015:76:489-98

86 O'Reilly EM, Lee JW, Zalupski M, et al. Randomized, Multicenter, Phase II Trial of Gemcitabine and Cisplatin With or Without Veliparib in Patients With Pancreas Adenocarcinoma and a Germline BRCA/PALB2 Mutation. JCO 2020;38:1378-88.

87 Lowery MA, Kelsen DP, Stadler ZK, et al. An Emerging Entity: Pancreatic Adenocarcinoma Associated with a Known BRCA Mutation: Clinical Descriptors, Treatment Implications, and Future Directions. Oncologist 2011;16:1397-402.

88 Hegewisch-Becker S, Aldaoud A, Wolf T, et al. Results from the prospective German TPK clinical cohort study: treatment algorithms and survival of 1,174 patients with locally advanced, inoperable, or metastatic pancreatic ductal adenocarcinoma. Int J Cancer 2019;144:981-90

89 Yu S, Agarwal P, Mamtani R, et al. Retrospective Survival Analysis of Patients With Resected Pancreatic Ductal Adenocarcinoma and a Germline BRCA or PALB2 Mutation. JCO Precision Oncology 2019;3:1-11.

90 Kamarajah SK, Bundred JR, Alrawashdeh W, et al. A systematic review and network meta-analysis of phase III randomised controlled trials for adjuvant therapy following resection of pancreatic ductal adenocarcinoma (PdaC). HPB 2020;22:649-59.

91 Lin K-I, Yang J-L, Lin Y-C, et al. Network meta-analysis of efficacy and safety of chemotherapy and target therapy in the first-line setting of advanced pancreatic cancer. Cancers 2019;11:1746.

92 Rebelatto TF, Falavigna M, Pozzari M, et al. Should platinum-based chemotherapy be preferred for germline breast cancer genes (BRCA) 1 and 2-mutated pancreatic ductal adenocarcinoma ( $\mathrm{PdaC}$ ) patients? A systematic review and meta-analysis. Cancer Treat Rev 2019;80:101895.

93 Pokataev I, Fedyanin M, Polyanskaya E, et al. Efficacy of platinum-based chemotherapy and prognosis of patients with pancreatic cancer with homologous recombination deficiency: comparative analysis of published clinical studies. ESMO Open 2020;5:e000578.

94 Pilié PG, Tang C, Mills GB, et al. State-Of-The-Art strategies for targeting the DNA damage response in cancer. Nat Rev Clin Oncol 2019;16:81-104.

95 Shroff RT, Hendifar A, McWilliams RR, et al. Rucaparib Monotherapy in Patients With Pancreatic Cancer and a Known Deleterious BRCA Mutation. JCO Precis Oncol 2018;2018:15

96 Kaufman B, Shapira-Frommer R, Schmutzler RK, et al. Olaparib monotherapy in patients with advanced cancer and a germline BRCA1/2 mutation. J Clin Oncol 2015:33:244-50.

97 Lowery MA, Kelsen DP, Capanu M, et al. Phase II trial of veliparib in patients with previously treated BRCA-mutated pancreas ductal adenocarcinoma. Eur J Cancer 2018;89:19-26.

98 Chiorean EG, Guthrie KA, Philip PA, et al. Randomized phase II study of second-line modified FOLFIRI with PARP inhibitor ABT-888 (veliparib) (NSC-737664) versus FOLFIRI in metastatic pancreatic cancer (mPC): SWOG S1513. Journal of Clinical Oncology 2019:37:4014.

99 Pishvaian MJ, Wang $\mathrm{H}$, Parenti S, et al. Final report of a phase I/II study of veliparib (vel) in combination with 5-FU and oxaliplatin (FOLFOX) in patients (PTS) with metastatic pancreatic cancer (mPDAC). Journal of Clinical Oncology 2019;37:4015.

100 Golan T, Hammel P, Reni M, et al. Maintenance Olaparib for Germline BRCA-Mutated Metastatic Pancreatic Cancer. N Engl J Med 2019;381:317-27.

101 Binder KAR, Mick R, O'Hara M, et al. Abstract CT234: A Phase II, single arm study of maintenance rucaparib in patients with platinum-sensitive advanced pancreatic cancer and a pathogenic germline or somatic mutation in BRCA1, BRCA2 or PALB2\&gt. Cancer Research 2019:79:CT234-CT.

102 O'Reilly EM, Lee JW, Lowery MA, et al. Phase 1 trial evaluating cisplatin, gemcitabine, and veliparib in 2 patient cohorts: germline BRCA mutation carriers and wild-type BRCA pancreatic ductal adenocarcinoma. Cancer 2018;124:1374-82
103 Yarchoan M, Myzak MC, Johnson BA, et al. Olaparib in combination with irinotecan, cisplatin, and mitomycin $\mathrm{C}$ in patients with advanced pancreatic cancer. Oncotarget 2017;8:44073-81.

104 Hammel P, Kindler HL, Reni M, et al. Health-Related quality of life in patients with a germline BRCA mutation and metastatic pancreatic cancer receiving maintenance olaparib. Ann Oncol 2019;30:1959-68.

105 Adiseshaiah PP, Crist RM, Hook SS, et al. Nanomedicine strategies to overcome the pathophysiological barriers of pancreatic cancer. Nat Rev Clin Oncol 2016;13:750-65.

106 Martino C, Pandya D, Lee R, et al. ATM-Mutated pancreatic cancer: clinical and molecular response to Gemcitabine/Nab-Paclitaxel after genome-based therapy resistance. Pancreas 2020;49:143-7.

107 Armstrong SA, Schultz CW, Azimi-Sadjadi A, et al. Atm dysfunction in pancreatic adenocarcinoma and associated therapeutic implications. Mol Cancer Ther 2019;18:1899-908.

108 Norquist B, Wurz KA, Pennil CC, et al. Secondary somatic mutations restoring BRCA1/2 predict chemotherapy resistance in hereditary ovarian carcinomas. J Clin Oncol 2011;29:3008-15

109 Franzese E, Centonze S, Diana A, et al. Parp inhibitors in ovarian cancer. Cancer Treat Rev 2019;73:1-9.

110 Glazer PM, Hegan DC, Lu Y, et al. Hypoxia and DNA repair. Yale J Biol Med 2013:86:443-51.

111 Rey S, Schito L, Wouters BG, et al. Targeting hypoxia-inducible factors for antiangiogenic cancer therapy. Trends Cancer 2017:3:529-41.

112 Ibrahim YH, García-García C, Serra V, et al. Pi3K inhibition impairs BRCA1/2 expression and sensitizes BRCA-proficient triple-negative breast cancer to PARP inhibition. Cancer Discov 2012;2:1036-47

113 Konstantinopoulos PA, Barry WT, Birrer M, et al. Abstract CT008: phase I study of the alpha specific PI3-kinase inhibitor BYL719 and the poly (ADP-ribose) polymerase (PARP) inhibitor olaparib in recurrent ovarian and breast cancer: analysis of the dose escalation and ovarian cancer expansion cohort. Cancer Research 2017;77:CT008-CT.

114 Karnak D, Engelke CG, Parsels LA, et al. Combined inhibition of Wee1 and PARP1/2 for radiosensitization in pancreatic cancer. Clin Cancer Res 2014;20:5085-96.

115 Roberti M, Schipani F, Bagnolini G, et al. Rad51/BRCA2 disruptors inhibit homologous recombination and synergize with olaparib in pancreatic cancer cells. Eur J Med Chem 2019;165:80-92

116 Abida W, Bang YJ, Carter L, et al. Abstract A094: phase I modular study of AZD0156, a first-in-class oral selective inhibitor of ataxia telangiectasia mutated protein kinase (ATM), in combination with olaparib (atom study, module 1). Molecular Cancer Therapeutics 2018;17:A094-A.

117 Nevala-Plagemann C, Hidalgo M, Garrido-Laguna I. From state-of-the-art treatments to novel therapies for advanced-stage pancreatic cancer. Nat Rev Clin Oncol 2020;17:108-23

118 Macherla S, Laks S, Naqash AR, et al. Emerging role of immune checkpoint blockade in pancreatic cancer. Int J Mol Sci 2018;19. doi:10.3390/ijms19113505

119 Zhang Q, Green MD, Lang X, et al. Inhibition of ATM increases interferon signaling and sensitizes pancreatic cancer to immune checkpoint blockade therapy. Cancer Res 2019:79:3940-51.

120 Karzai F, Madan RA, Owens $\mathrm{H}$, et al. A phase 2 study of olaparib and durvalumab in metastatic castrate-resistant prostate cancer (mCRPC) in an unselected population. Journal of Clinical Oncology 2018;36:163.

121 Domchek SM, Postel-Vinay S, Im S-A, et al. Olaparib and durvalumab in patients with germline BRCA-mutated metastatic breast cancer (MEDIOLA): an open-label, multicentre, phase 1/2, basket study. Lancet Oncol 2020. doi:10.1016/S14702045(20)30324-7. [Epub ahead of print: 06 Aug 2020].

122 O'Reilly EM, DY O, Dhani N, et al. Durvalumab with or without tremelimumab for patients with metastatic pancreatic ductal adenocarcinoma: a phase 2 randomized clinical trial. JAMA Oncol 2019.

123 Bailey P, Chang DK, Nones K, et al. Genomic analyses identify molecular subtypes of pancreatic cancer. Nature 2016;531:47-52.

124 Hoadley KA, Yau C, Hinoue T, et al. Cell-of-Origin patterns dominate the molecular classification of 10,000 tumors from 33 types of cancer. Cell 2018;173:291-304.

125 Witkiewicz AK, McMillan EA, Balaji U, et al. Whole-Exome sequencing of pancreatic cancer defines genetic diversity and therapeutic targets. Nat Commun 2015;6:6744.

126 Sehdev A, Gbolahan 0, Hancock BA, et al. Germline and somatic DNA damage repair gene mutations and overall survival in metastatic pancreatic adenocarcinoma patients treated with Folfirinox. Clin Cancer Res 2018;24:6204-11.

127 Kondo T, Kanai M, Kou T, et al. Association between homologous recombination repair gene mutations and response to oxaliplatin in pancreatic cancer. Oncotarget 2018;9:19817-25.

128 Palacio S, McMurry HS, Ali R, et al. Dna damage repair deficiency as a predictive biomarker for Folfirinox efficacy in metastatic pancreatic cancer. J Gastrointest Oncol 2019:10:1133-9.

129 Wattenberg MM, Asch D, Yu S, et al. Platinum response characteristics of patients with pancreatic ductal adenocarcinoma and a germline BRCA1, BRCA2 or PALB2 mutation. Br J Cancer 2020;122:333-9.

130 Blair AB, Groot VP, Gemenetzis G, et al. Brca1/Brca2 germline mutation carriers and sporadic pancreatic ductal adenocarcinoma. J Am Coll Surg 2018;226:630-7. 